\title{
Formação Taciba: última manifestação glacial no Paraná
}

\author{
Taciba Formation: the last glacial episode in Paraná State
}

\author{
THAMMY ELLIN MOTTIN ${ }^{1} \&$ FERNANDO FARIAS VESELY ${ }^{2}$
}

${ }^{1}$ Programa de Pós-Graduação de Geologia (PPGEOL) - UFPR, Brasil, https://orcid.org/0000-0002-6256-6769, thammymottin@gmail.com

${ }^{2}$ Universidade Federal do Paraná (UFPR), Brasil, https://orcid.org/0000-0002-6741-8589, veselyff@gmail.com

\begin{abstract}
Resumo
A Era Glacial Neopaleozoica e a transição completa para condições pós-glaciais são considerados eventos climáticos únicos na história geológica. O principal registro de tais eventos está nas bacias sedimentares gondwânicas, que sugerem uma glaciação dinâmica marcada por repetidos períodos glaciais e interglaciais. A Bacia do Paraná abriga o registro mais espesso e geograficamente extenso da glaciação, referido como Grupo Itararé. Este trabalho pretende analisar o registro da última influência das geleiras neopaleozoicas no norte da Bacia do Paraná e a natureza da transição para os estratos pós-glaciais da Formação Rio Bonito. A região de Ibaiti, no nordeste do Paraná, foi escolhida como área de estudo por conter uma das maiores espessuras da Formação Taciba na bacia e por necessitar de estudos de maior detalhe, capazes de refinar a estratigrafia e história deposicional. Para tal, foram empregados métodos sedimentológicos (levantamento de fácies, associações de fácies, perfis estratigráficos verticais) e mapeamento geológico. Ademais, foram traçadas correlações estratigráficas entre perfis de afloramento e perfis de raios-gama de poços profundos. A Formação Taciba apresenta espessuras de cerca de $150 \mathrm{~m}$ e foi subdividida em três unidades genéticas mapeáveis: 1) depósitos proglaciais, dispostos em um padrão de granodecrescência ascendente e que incluem conglomerados, arenitos, diamictitos e lamitos; 2) depósitos deltaicos, compreendendo ritmitos, heterolitos e arenitos empilhados em um padrão de granocrescência ascendente; e 3) depósitos glácio-marinhos ressedimentados, englobando diamictitos que definem um padrão granocrescente ascendente. Afinidade glacial nas unidades 1 e 3, e decréscimo/ausência de evidência glacial na unidade 2 sugerem dois episódios distintos de avanço glacial, separados por uma fase interglacial. As tendências deposicionais definidas em superfície prolongam-se por centenas de quilômetros bacia adentro. A passagem glacial-pós-glacial no norte da bacia é abrupta, definida por uma superfície erosiva associada à formação de paleossolo e vales incisos no topo da unidade 3 .
\end{abstract}

Palavras-chave: Grupo Itararé, Glaciação Neopaleozoica, Bacia do Paraná

\begin{abstract}
The Late Paleozoic Ice Age (LPIA) and the transition to fully postglacial conditions are considered unique climatic events within the geological history. The main record of these events is encompassed by the gondwanic sedimentary basins, that suggest a dynamic glaciation punctuated by repeated glacial and interglacial events. The Paraná Basin holds the thickest and geographically more significative record of the LPIA, referred to as the Itarare Group. This work aims to analyze the record of the demise of the Late Paleozoic glaciers in northern Parana Basin and the nature of the contact with the postglacial Rio Bonito Formation. The Ibaiti region in northeast Paraná State has been chosen as study area because it contains one of the thickest successions of the upper Itararé Group (Taciba Formation) and because of the need of high-resolution studies capable to refine its stratigraphy and depositional history. For this, we conducted sedimentological analysis (facies and facies association description and measurement of stratigraphic logs) and geological mapping. Furthermore, we performed stratigraphic correlations using gamma-ray logs from deep wells. The Taciba Formation is ca. $150 \mathrm{~m}$-thick and was subdivided into three mappable genetic depositional units: 1) proglacial deposits, stacked in a fining-upward motif, including conglomerates, sandstones, diamictites and mudstones; 2) deltaic deposits, with a coarsening-upward pattern, and including rhythmites, heterolithics and sandstones; and 3) resedimented glaciomarine deposits encompassing diamictites stacked in a fining-upward pattern. Glacial affinity within units 1 and 3 and the decreasel absence of glacial evidence within unit 2 suggest two distinct glacial advances interspersed with an interglacial phase. The depositional stacking patterns defined in outcrops extents for hundreds of kilometers into de basin, according to the correlations. The glacial-postglacial transition is sharp, defined by an erosive surface related to paleosol and incised valleys development.
\end{abstract}

Keywords: Itararé Group, Taciba Formation, Late Paleozoic Ice Age 


\section{Introdução}

A Era Glacial Neopaleozoica (Late Paleozoic Ice Age-LPIA) foi o episódio glacial mais duradouro e de maior extensão geográfica do Fanerozoico, tendo marcado direta e indiretamente o registro sedimentar de bacias paleozoicas de diferentes latitudes (e.g., Isbell et al., 2003; Montañez e Poulsen, 2013). A glaciação ocorreu simultaneamente a eventos geológicos singulares do final do Paleozoico, como o posicionamento de grandes massas continentais em altas latitudes sul, reconfigurações tectônicas de grande escala, importantes flutuações dos níveis de $\mathrm{O} 2$ e $\mathrm{CO} 2$ atmosféricos e expansão de florestas paleotropicais. Estes eventos geológicos são considerados geneticamente relacionados com o início, evolução e término da LPIA (e.g., Cleal e Thomas, 2005; Isbell et al., 2012).

A LPIA foi pontuada por diversos episódios glaciais com duração estimada de 1 a $8 \mathrm{Ma}$, alternados com períodos interglaciais de duração semelhante (e.g., Isbell et al., 2003; 2012; Fielding et al., 2008). Múltiplos centros glaciais diácronos, de dimensões moderadas, propagavam-se através do Gondwana, influenciando a sedimentação das bacias gondwânicas. O registro sedimentar da $L P I A$ abrigado pela Bacia do Paraná é referido como Grupo Itararé, cujos depósitos foram formados entre o Mississipiano e o Eopermiano (Souza, 2006; Rosa et al., 2019).

A passagem de condições glaciais (icehouse) da LPIA para condições pós-glaciais (greenhouse) no Neopaleozoico é considerada um evento único na história da Terra, servindo de análogo ao atual estado climático do planeta e à futura transição para um estado de greenhouse. Apenas a LPIA encerra a completa transição glacial-pós-glacial em um planeta biologicamente complexo (Gastaldo et al., 1996). Os depósitos do Grupo Itararé são considerados os mais espessos e completos desse episódio no Gondwana, compreendendo o registro de grande parte da referida glaciação. Dessa forma, constitui uma excelente oportunidade para a reconstrução dos últimos estágios glaciais na bacia, que precederam a passagem completa para um estágio pós-glacial.

Este trabalho é um estudo complementar ao trabalho prévio de Mottin et al. (2018). Foram empregados métodos de campo, incluindo análise de fácies, associações de fácies e paleocorrentes, além de correlações estratigráficas entre perfis de poços e afloramentos, visando reconstruir o último estágio glacial neopaleozoico no estado do Paraná. A área estudada em superfície compreende a região de Ibaiti, nordeste do Paraná, onde aflora uma sucessão de aproximadamente $150 \mathrm{~m}$ entre o topo do Grupo Itararé (Formação Taciba) e base da Formação Rio Bonito (e.g., Zacharias, 2004; Vesely e Assine, 2004; 2006; Mottin et al., 2018). Os resultados obtidos permitiram definir um arcabouço estratigráfico de maior resolução que estudos prévios, reconstruir a evolução sedimentar com relação a ciclos glaciais e subdividir a Formação Taciba, até então indivisa nessa área, em três unidades geneticamente relacionadas.

\section{Contexto geológico e área de estudo}

A Bacia do Paraná, instalada no interior cratônico do Gondwana, registra episódios geológicos de diversas naturezas ocorridos entre o Ordoviciano e o Neocretáceo, dentre os quais a LPIA. Os registros de glaciação estão incluídos no Grupo Itararé, unidade depositada entre o Viseano (Carbonífero) e o Sakmariano (Eopermiano) e que encerra a sucessão sedimentar glacial mais espessa e de maior extensão geográfica entre as unidades neopaleozoicas correlatas do Gondwana (Souza, 2006; Rocha-Campos et al., 2008; Holz et al., 2010; Rosa et al., 2019).

O Grupo Itararé possui espessuras de até $1300 \mathrm{~m} \mathrm{em}$ subsuperfície e de até $800 \mathrm{~m}$ em superfície (França e Potter, 1988; Vesely e Assine, 2004). A unidade apresenta um onlap em direção ao sul, de forma que o registro mais completo da glaciação se encontra na porção norte da bacia, entre o norte do Paraná e sul de São Paulo (e.g., Vesely e Assine, 2004; 2006). No extremo sul da bacia (Rio Grande do Sul e sul de Santa Catarina) o registro da glaciação não ultrapassa $150 \mathrm{~m}$ de espessura (Holz et al., 2008). A unidade é caracterizada por grande diversidade faciológica, incluindo fácies distintivas como diamictitos e ritmitos, bem como arenitos, folhelhos e conglomerados. Sua afinidade glacial é evidenciada principalmente por pavimentos estriados, deformações glaciotectônicas, estratos com clastos caídos e diamictitos contendo clastos facetados e estriados (Santos et al., 1996; Vesely e Assine, 2006, Rocha-Campos, 2008; Rosa et al., 2019).

$\mathrm{Na}$ faixa de afloramentos do estado do Paraná o Grupo Itararé encerra quatro formações: Lagoa Azul, Campo do Tenente, Campo Mourão e Taciba, em ordem estratigráfica ascendente (Vesely et al. 2021; neste volume). A Formação Taciba, originalmente definida em subsuperfície por França \& Potter (1988) e objeto deste estudo, abriga o registro da última manifestação geológica das geleiras neopaleozoicas na Bacia do Paraná. Idades da unidade são controversas, provenientes de datações radiométricas e palinologia. Os dados oriundos de datação radiométrica estão concentrados exclusivamente no extremo sul da bacia e posicionam a Formação Taciba e, consequentemente, a deglaciação final do Grupo Itararé, no Neocarbonífero (Cagliari et al., 2016; Griffis et al., 2018). A palinologia posiciona este intervalo dentro da Subzona basal Protohaploxypinus goraiensis da Zona de Intervalo Vittatina costabilis ( $V c Z$ ). A $V c Z$ compreende depósitos da parte superior do Grupo Itararé e base da Formação Rio Bonito e engloba tanto estratos neocarboníferos quanto eopermianos (Souza, 2006).

O Grupo Itararé foi anteriormente estudado no norte do estado do Paraná por Vesely e Assine (2004; 2006), os quais definiram o empilhamento estratigráfico da unidade com base em dados de afloramentos e subdividiram-na em cinco sequências de deglaciação. A partir da correlação entre o perfil vertical composto de superfície e poços profundos, Vesely e Assine (2004) associaram as sequências de deglaciação com as unidades propostas por França e Potter (1988). Dessa forma, a última sequência de deglaciação (Sequência 5) definida por Vesely \& Assine (2004) correlaciona-se com a Formação Taciba de França e Potter (1988). O trabalho de Mottin et al. (2018) reexaminou o intervalo correspondente à Formação Taciba na região de Ibaiti, definindo um arcabouço estratigráfico, paleoambiental e paleogeografico mais detalhado. 
O Grupo Itararé é sucedido pela Formação Rio Bonito, depositada em um contexto puramente pós-glacial, em ambiente transicional sob influência de transgressões e regressões (Medeiros e Thomaz Filho, 1973). A unidade é composta em grande parte por arenitos, siltitos e folhelhos, e subordinadamente por carvão e calcário. Encerra os membros Triunfo, Paraguaçu e Siderópolis, da base para o topo (Schneider et al., 1974). Na região nordeste do Paraná, o Grupo Itararé pode estar em contato com o Membro Triunfo, e, quando da ausência deste, diretamente sob o Membro Paraguaçu. O contato se dá por uma superfície discordante com a presença de vales incisos desenvolvidos no topo dos diamictitos da Formação Taciba (Zacharias, 2004).

A natureza do contato entre o Grupo Itararé e a Formação Rio Bonito é distinta nas partes norte e sul da Bacia do Paraná. Na porção meridional, o contato foi descrito como transicional, em que pelitos que representariam o prodelta são atribuídos ao Grupo Itararé, e estes são progressivamente recobertos por heterolitos e arenitos de ambiente flúvio-deltaico da Formação Rio Bonito (e.g., Medeiros e Thomaz Filho, 1973; Schemiko et al., 2019). Na parte setentrional, por outro lado, autores como Soares e Cava (1982), Castro et al. (2004), Zacharias e Assine (2005) e Weinschütz e Castro (2006) entendem que a Formação Rio Bonito se assenta em contato erosivo e discordante sobre fácies marinhas da Formação Taciba.

\section{Métodos}

A fim de caracterizar o último estágio glacial do Grupo Itararé na parte norte da Bacia do Paraná e a passagem glacial-pós-glacial, uma área representativa deste intervalo foi selecionada na faixa aflorante leste da bacia, no nordeste do estado do Paraná. A área de aproximadamente $300 \mathrm{~km}^{2}$ abrange parte dos municípios de Ibaiti, Pinhalão e Japira, onde aflora a porção superior do Grupo Itararé (Formação Taciba) e base do Grupo Guatá (Formação Rio Bonito; Fig. 1).

Para tal, fácies sedimentares e associações de fácies foram descritas em detalhe em 110 afloramentos, perfis

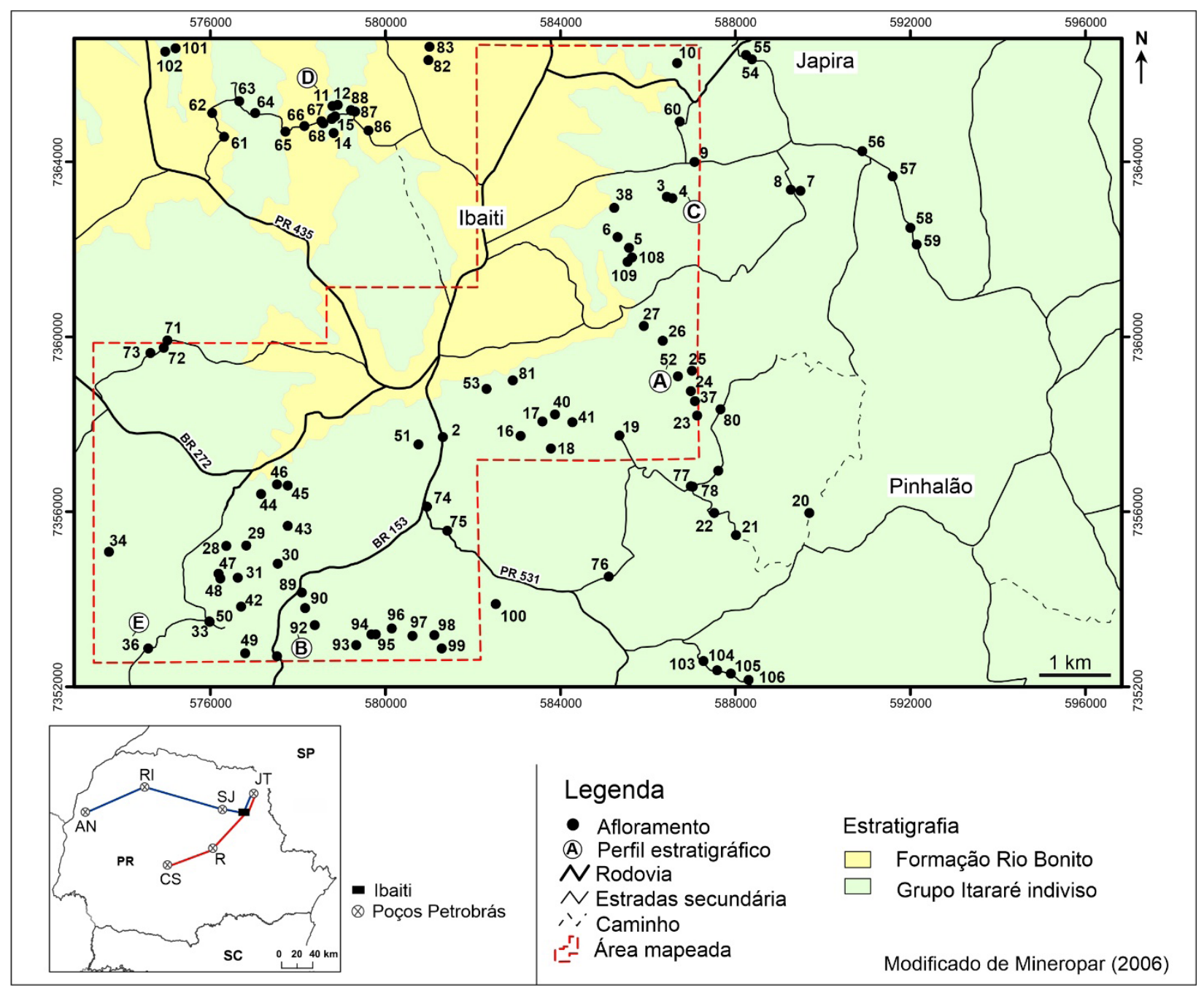

Figura 1 - Mapa geológico simplificado da área estudada, com a localização dos afloramentos, perfis estratigráficos e área mapeada em escala 1:10.000. Notar no canto inferior esquerdo, mapa do Estado do Paraná indicando a localização da área de estudo e dos poços da Petrobras utilizados na correlação estratigráfica. Abreviações: AN Altônia, RI Rio Ivaí, SJ São Jerônimo da Serra, JT Joaquim Távora, CS Chapéu do Sol, R Reserva. O polígono delimitado em linha vermelha tracejada (área mapeada) indica a localização da figura 2. 
estratigráficos verticais foram levantados para documentar a sucessão vertical de fácies, e paleocorrentes $(n=756)$ foram medidas nas diferentes unidades para entender o padrão de dispersão sedimentar. As medidas de paleocorrentes foram tomadas em estratificações cruzadas acanaladas, planares e ripples em arenitos e ritmitos. Mapeamento em escala 1:10.000 foi realizado em uma área que concentra a maior parte dos afloramentos (Fig. 1), possibilitando a subdivisão litoestratigráfica da Formação Taciba e um refinamento da posição do contato glacial-pós-glacial.

A fim de verificar se as tendências deposicionais observadas em superfície estendem-se lateralmente, foi conduzida uma correlação do perfil estratigráfico composto obtido em afloramentos com perfis de poços. Para tanto, foram selecionados poços exploratórios perfurados pela Petrobras e Paulipetro e definidas duas direções de correlação (W-E e SW-NE). Os poços utilizados na correlação são: 1-CS-2-PR, 1-R-1-PR, 1-SJ-1-PR, 1-JT1-PR, 2-AN-1-PR E 2-RI-1-PR (Fig. 1). O pico de radioatividade localizado aproximadamente na porção média da Formação Taciba foi utilizado como horizonte de referência (datum).

\section{Estratigrafia da Formação Taciba}

A Formação Taciba encerra uma sucessão sedimentar de aproximadamente $150 \mathrm{~m}$ (Fig. 2), marcada por uma unidade basal com padrão geral de granodecrescência ascendente que culmina com pacote de diamictito no topo, uma sucessão intermediária com padrão de granocrescência ascendente, com lamitos gradativamente substituídos por arenitos, e uma unidade superior composta por diamictitos, que descreve um padrão de granodecrescência ascendente. A unidade superior está em contato abrupto com a base da Formação Rio Bonito, do Grupo Guatá.

Dessa forma, foram definidas e mapeadas três unidades deposicionais (Figs. 2 e 3), englobando, da base para o topo, depósitos proglaciais (unidade 1), deltaicos (unidade 2), e glácio-marinhos ressedimentados (unidade 3). Dezessete fácies sedimentares compõem o arcabouço da Formação Taciba, cujas descrições, interpretações e aspectos visuais são apresentados na Tabela 1. Em termos litoestratigráficos, a porção inferior, arenítica, da unidade 1 corresponde ao Membro Rio Segredo, ao passo que o restante da sucessão (topo da unidade 1, unidade 2 e unidade 3 correspondem ao Membro Chapéu do Sol. Os arenitos da unidade 2 vem sendo designados informalmente como "arenito Engano", em alusão ao vale do rio homônimo a noroeste de Ibaiti (Vesely et al., 2021; neste volume).

\subsection{Unidades deposicionais: descrição e interpretação}

\section{Unidade 1: Depósitos Proglaciais (Dm, Dres, Gm, Gg,} Sg, Sm1, Sm2, St1, St2, Sr, Sres, Ss, Sh, Fm e Fh)

Trata-se da unidade basal da Formação Taciba, composta pela associação de conglomerados, arenitos, lamitos e diamictitos (Tab. 1). A unidade 1 possui espessuras entre 60 e 70 m, exibindo uma tendência de granodecrescência ascendente, em que conglomerados e arenitos são sucedidos por diamictitos no topo. O contato com a unidade 2, sobrejacente, é abrupto (Fig. 2).
A unidade 1 consiste essencialmente em intercalações entre arenitos predominantemente mal selecionados, maciços a estratificados e conglomerados maciços a gradados, arranjados em múltiplos ciclos de granodecrescência ascendente de espessuras variáveis (Figs. 2 e 3). A presença de clastos polimíticos, variando de grânulos a blocos, distribuidos aleatoriamente ou alinhados, é comum nas fácies arenosas (Figs. 3 e 4A). Clastos caídos (dropstones) são raros e ocorrem preferencialmente na base da unidade, enquanto clastos estriados ocorrem na base e topo (Fig. 3, 4C e 4D).

Feições de deformação são abundantes ao longo de toda a unidade e podem ser agrupadas em duas categorias: estruturas de deformação penecontemporâneas, consistindo em dobras, falhas e injeções clásticas (Fig. 4G), e estruturas de deformação de sedimentos inconsolidados, incluindo estruturas de carga, em chama, de escape de fluidos e diques clásticos (Fig. 4B). Fácies lamosas (argilitos e diamictitos) ocorrem subordinamamente, intercaladas a fácies arenosas (Fig. 3). O diamictito do topo da unidade 1 é lateralmente contínuo na área de estudo, com espessuras superiores a $10 \mathrm{~m}$. Apresenta estruturas de deformação penecontemporânea, como dobras, falhas e injeções de areia, além de blocos alóctones de arenito e conglomerado deformados (Figs. 4F e G).

A deposição da unidade 1 ocorreu em ambiente proglacial subaquoso (leques de outwash), promovida pela liberação de fluxos de água de degelo e fluxos gravitacionais de massa associados. De forma geral, as seguintes evidências suportam a interpretação desse ambiente: i) recorrência e agradação de fácies de granulação grossa e mudanças abruptas de fácies (e.g., Lajeunesse e Allard, 2002; Russell e Arnott, 2003); ii) presença de clastos caídos, facetados e estriados, indicando uma origem glacial para estes sedimentos; iii) camadas com deformações de sedimentos inconsolidados e deformações plásticas (e.g., Lønne, 1995; Henry et al., 2012; Aquino et al., 2016); e iv) gradação lateral de fácies arenosas para diamictitos e lamitos (e.g., Koch e Isbell, 2013).

A intercalação de múltiplos ciclos de granodecrescência sugere mudanças cíclicas nas condições do fluxo, relacionadas a variações na descarga da água de degelo. Porém, um padrão geral de granodecrescência ascendente é observado, relacionado à tendência de diminuição granulométrica fluxo abaixo comum neste ambiente (e.g., Russel e Arnott, 2003; Winsemann et al., 2009; Koch e Isbell, 2013; Aquino et al., 2016).

Conglomerados e arenitos predominantemente mal selecionados, maciços a gradados, teriam se depositado na parte proximal de leques subaquosos de outwash. De acordo com Mulder e Alexander (2001), fluxos densos hiperconcentrados são os principais responsáveis pela formação de depósitos grossos e maciços, onde a geração de estruturas tracionais é inibida devido à alta concentração de carga suspensa. Arenitos portando laminação horizontal, estratificação cruzada acanalada e ondulações de corrente representam deposição em porções relativamente mais distais dos sistemas de outwash, sob condições de regime de fluxo superior ou inferior, e onde os fluxos derivados de água de degelo têm a tendência de desaceleração (Aquino et al., 2016). A presença de ma- 


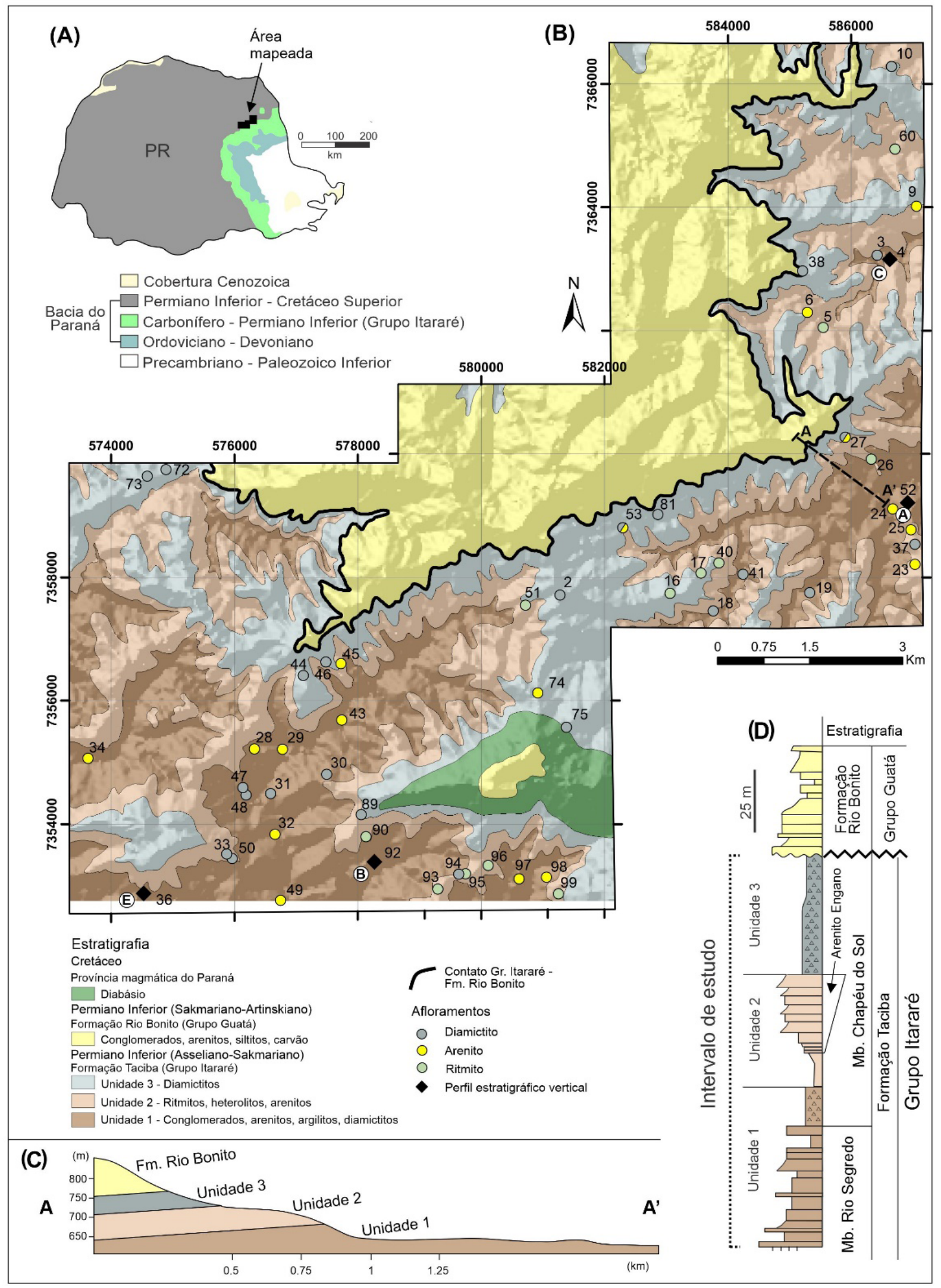

Figura 2 - (A) Contextualização da área mapeada na geologia do Estado do Paraná (modificado de Mineropar, 2006). (B) Mapa geológico de detalhe elaborado para parte da área de estudo, em que a Formação Taciba é subdividida em três unidades genéticas. O contato com a Formação Rio Bonito, pós-glacial, é evidenciado pela linha preta espessa (C). Seção geológica esquemática A-A' mostrando o empilhamento estratigráfico da Formação Taciba, espessuras das unidades e o contato com a Formação Rio Bonito. (D) Representação das unidades mapeadas no empilhamento estratigráfico da Formação Taciba. Nomenclatura litoestratigráfica de acordo com Vesely et al. (2021; neste volume). 


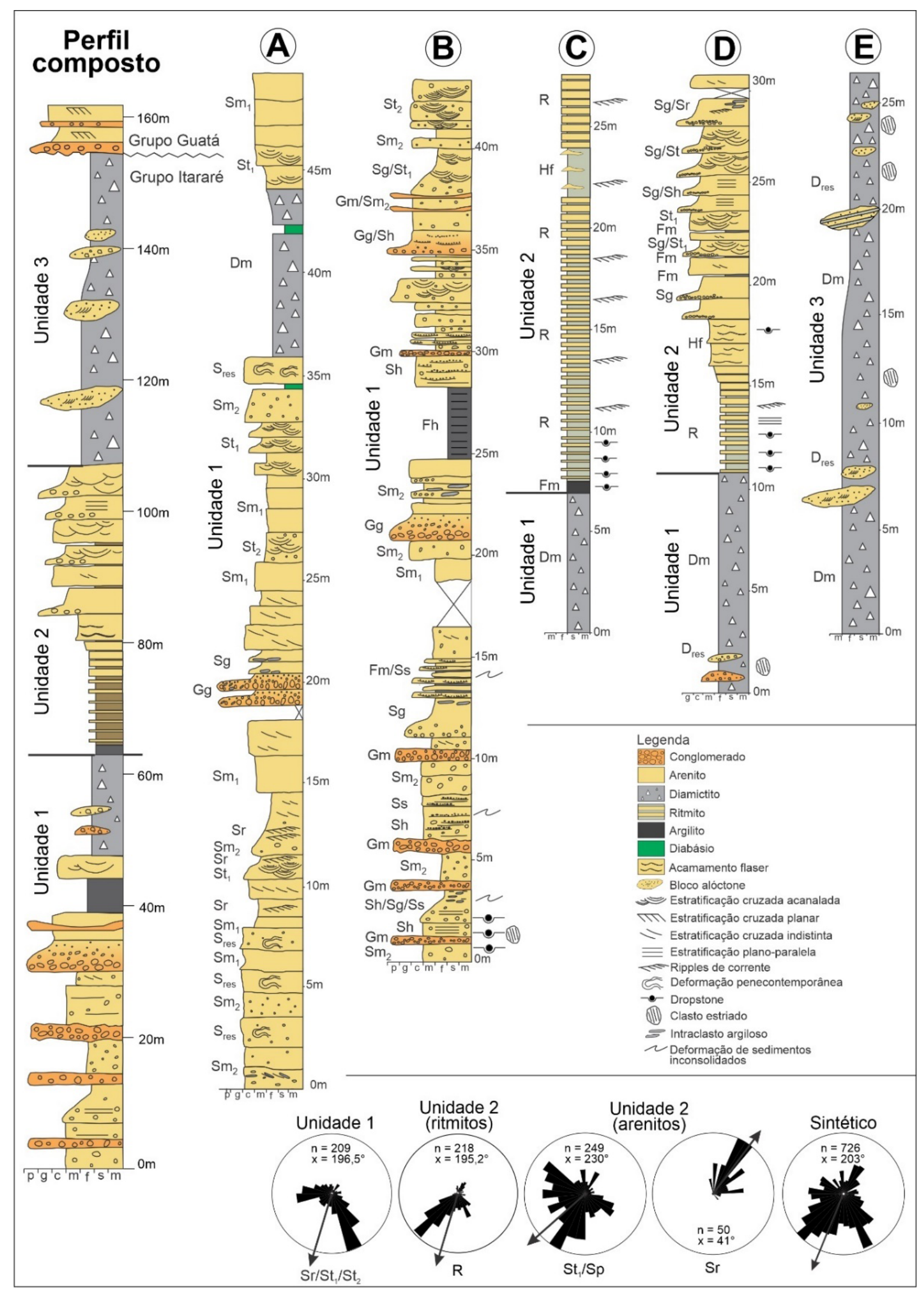

Figura 3 - Perfil vertical composto do intervalo estudado (A) e perfis estratigráficos representativos das três unidades deposicionais (B). Diagramas de roseta das unidades 1 e 2 e o diagrama sintético são mostradas na parte inferior da figura (modificado de Mottin et al., 2018). 


\begin{tabular}{|c|c|c|c|c|}
\hline Facies & Litologia & Estrutura sedimentar & Processo deposicional & Aspecto \\
\hline $\mathrm{Dm}$ & $\begin{array}{l}\text { Diamictito matriz-suportado com clastos } \\
\text { polimíticos (grânulo a bloco) dispersos em } \\
\text { matriz lamo-arenosa; Abundantes clastos } \\
\text { angulosos, estriados e facetados }\end{array}$ & Maciça & $\begin{array}{l}\text { Ressedimentação via fluxo de detritos } \\
\text { subaquoso ou chuva de detritos derivada de } \\
\text { água de degelo associada a queda de clastos } \\
\text { transportados por icebergs }\end{array}$ & - \\
\hline Dres & $\begin{array}{l}\text { Diamictito matriz-suportado (argila a areia } \\
\text { fina) com clastos polimíticos (grânulo a } \\
\text { blocos); Abundantes clastos angulosos, } \\
\text { estriados e facetados }\end{array}$ & $\begin{array}{l}\text { Blocos alóctones de arenitos, conglomerados } \\
\text { e ritmitos, deformados ou não; Diâmetro entre } \\
15 \mathrm{~cm} \text { e } 20 \mathrm{~m} \text {; Comumente orientados } \\
\text { segundo o comprimento. Matriz pode estar } \\
\text { deformada }\end{array}$ & $\begin{array}{l}\text { Deposição por transporte em massa em } \\
\text { ambiente subaquoso, via escorregamentos }\end{array}$ & \\
\hline $\mathrm{Fm}$ & Argilito cinza escuro & Maciça & $\begin{array}{l}\text { Suspensão de lama em ambiente subaquoso } \\
\text { de baixa energia }\end{array}$ & \\
\hline$R$ & $\begin{array}{l}\text { Ritmito composto de arenito muito fino } \\
\text { intercalado com lama (intercalação } \mathrm{mm} \text { a } \\
\mathrm{cm} \text { ), progressivamente mais arenoso para o } \\
\text { topo }\end{array}$ & $\begin{array}{l}\text { Ripples de corrente comumente apresentando } \\
\text { reversão de fluxo e drapes de argila ou } \\
\text { laminação paralela; Dropstones são pouco } \\
\text { abundantes; Localmente ocorrem icnofósseis } \\
\text { (Helminthoidichnites tenuis ) }\end{array}$ & $\begin{array}{l}\text { Correntes subaquosas de fundo associadas à } \\
\text { suspensão de finos. Ripples de corrente e } \\
\text { laminação paralela indicam regime de fluxo } \\
\text { inferior e superior, respectivamente. } \\
\text { Dropstones indicam gelo flutuante. Reversão } \\
\text { de fluxo e drapes são indícios de } \\
\text { retrabalhamento por maré }\end{array}$ & 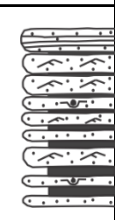 \\
\hline $\mathrm{Hf}$ & $\begin{array}{l}\text { Arenito fino a médio contendo lentes } \\
\text { descontínuas de argila (até } 10 \mathrm{~cm} \text { de } \\
\text { comprimento) }\end{array}$ & Acamamento flaser & $\begin{array}{l}\text { Migração de formas de leito sob regime de fluxo } \\
\text { inferior alternada com suspensão de finos. } \\
\text { Acamamento flaser aponta para atividade de } \\
\text { maré e dropstones indicam presença de } \\
\text { iceberg }\end{array}$ & 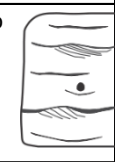 \\
\hline $\mathrm{Sr}$ & $\begin{array}{l}\text { Arenito fino à raramente médio, bem } \\
\text { selecionado }\end{array}$ & $\begin{array}{l}\text { Ripples de corrente, comumente } \\
\text { apresentando drapes e intraclastos argilosos } \\
\text { nos foresets }\end{array}$ & $\begin{array}{l}\text { Deposição sob regime de fluxo inferior } \\
\text { associado a suspensão; Drapes de argila } \\
\text { indicam ação de maré. }\end{array}$ & 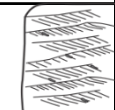 \\
\hline Ss & Camadas de arenito fino e grosso & $\begin{array}{l}\text { Estruturas dúcteis no contato entre camadas, } \\
\text { incluindo estruturas em chama, de carga e } \\
\text { laminações contorcidas }\end{array}$ & $\begin{array}{l}\text { Perturbação de sedimentos hidroplásticos } \\
\text { durante ou logo após a deposição, } \\
\text { provavelmente relacionada a altas taxas de } \\
\text { sedimentação (Allen, 1982) }\end{array}$ & \\
\hline Sred & Arenito médio a conglomerático & $\begin{array}{l}\text { Camadas basculadas, dobras reclinadas a } \\
\text { verticais, falhas normais e reversas } \\
\text { preenchidas ou não por injectitos de areia }\end{array}$ & $\begin{array}{l}\text { Ressedimentação em ambiente subaquoso, } \\
\text { provavelmente devido a processos de } \\
\text { escorregamento }\end{array}$ & \\
\hline $\mathrm{Sm}_{1}$ & Arenito médio a grosso & Maciça & $\begin{array}{l}\text { Deposição de fluxo não-coesivo } \\
\text { (hiperconcentrado a concentrado) (Mulder e } \\
\text { Alexander, 2001) }\end{array}$ & \\
\hline $\mathrm{Sg}$ & $\begin{array}{l}\text { Arenito conglomerático na base gradando a } \\
\text { arenito fino no topo }\end{array}$ & Gradação normal & $\begin{array}{l}\text { Fluxo gravitacional subaquoso, onde a } \\
\text { turbulência do fluxo e a interação grão-a-grão } \\
\text { mantém os sedimentos em suspensão; } \\
\text { Deposição é produto do decréscimo do } \\
\text { congelamento friccional }\end{array}$ & \\
\hline $\mathrm{St}_{1}$ & $\begin{array}{l}\text { Arenito fino a grosso, mal selecionado } \\
\text { textural e mineralogicamente }\end{array}$ & $\begin{array}{l}\text { Estratificação cruzada acanalada (sets entre } 3 \\
\mathrm{~cm} \text { a } 2 \text { m); Abundantes intraclastos argilosos } \\
\text { dispersos na rocha ou como drapes nos } \\
\text { planos da estratificação }\end{array}$ & $\begin{array}{l}\text { Migração de dunas de crista sinuosa } \\
\text { subaquosas sob regime de fluxo inferior; } \\
\text { Presença de abundantes intraclastos indica } \\
\text { erosão do substrato }\end{array}$ & \\
\hline $\mathrm{Sp}$ & $\begin{array}{l}\text { Arenito médio, medianamente selecionado } \\
\text { textural e mineralogicamente }\end{array}$ & $\begin{array}{l}\text { Estratificação cruzada planar (sets entre } 0,1 \text { e } \\
1 \mathrm{~m} \text { ) exibindo ritmicidade e drapes de argila } \\
\text { nos foresets }\end{array}$ & $\begin{array}{l}\text { Migração de dunas de crista reta subaquosas } \\
\text { sob regime de fluxo inferior. Ritmicidade da } \\
\text { estratificação mais drapes de argila sugerem } \\
\text { atividade de maré }\end{array}$ & \\
\hline Sh & $\begin{array}{l}\text { Arenito médio disposto em camadas } \\
\text { tabulares de cerca de } 0,5 \mathrm{~cm} \text { de espessura }\end{array}$ & $\begin{array}{l}\text { Laminação horizontal; Pode conter } \\
\text { dropstones e/ou clastos dispersos }\end{array}$ & $\begin{array}{l}\text { Transporte de carga de fundo sob regime de } \\
\text { fluxo superior; Dropstones indicam presença } \\
\text { de iceberg }\end{array}$ & \\
\hline $\mathrm{Sm}_{2}$ & $\begin{array}{l}\text { Arenito grosso com clastos dispersos, } \\
\text { variando de grânulo a bloco }\end{array}$ & Imbricação de clastos fraca a moderada & $\begin{array}{l}\text { Deposição de fluxo denso concentrado não- } \\
\text { coesivo (Mulder e Alexander, 2001) }\end{array}$ & 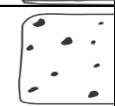 \\
\hline $\mathrm{St}_{2}$ & $\begin{array}{l}\text { Arenito conglomerático suportado por matriz } \\
\text { de areia grossa e clastos variando de } \\
\text { grânulo a bloco, dispersos aleatóriamente }\end{array}$ & $\begin{array}{l}\text { Estratificação cruzada acanalada (sets de até } \\
1 \mathrm{~m} \text { de espessura) }\end{array}$ & $\begin{array}{l}\text { Migração de dunas subaquosas de crista } \\
\text { sinuosa sob regime de fluxo inferior. Introdução } \\
\text { de clastos devido à ação de icebergs }\end{array}$ & \\
\hline $\mathrm{Gm}$ & $\begin{array}{l}\text { Conglomerado matriz-suportado a clasto- } \\
\text { suportado, com clastos de até } 30 \mathrm{~cm} \mathrm{em} \\
\text { uma matriz de areia muito grossa }\end{array}$ & Maciça a fracamente laminada & $\begin{array}{l}\text { Fluxo denso hiperconcentrado, possivelmente } \\
\text { relacionado a salto hidráulico (Mulder e } \\
\text { Alexander, 2001; Russel e Arnot, 2003) }\end{array}$ & \\
\hline $\mathrm{Gg}$ & $\begin{array}{l}\text { Conglomerado matriz-suportado, polimítico, } \\
\text { com grânulos a blocos imersos em matriz } \\
\text { de areia grossa }\end{array}$ & Gradação normal & $\begin{array}{l}\text { Deposição em ambiente subaquoso, por } \\
\text { processo impulsionado pela gravidade, com } \\
\text { uma componente de turbulência devido à } \\
\text { capacidade em selecionar as partículas (Miall, } \\
\text { 1978) }\end{array}$ & 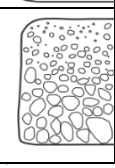 \\
\hline
\end{tabular}

Tabela 1 - Fácies sedimentares que compõem a Formação Taciba no nordeste do Paraná. 
tacões de até $2 \mathrm{~m}$ em arenitos com estratificação cruzada acanalada pode indicar a introdução destes por icebergs, visto que um fluxo capaz de transportar clastos destas dimensões não teria a capacidade de selecionar partículas e gerar formas de leito.
Fácies lamosas (argilitos e diamictitos maciços) intercaladas aos arenitos desta unidade representam sedimentação em porções distais de leques de outwash, por meio da decantação de lama de plumas flutuantes oriundas da água de degelo. Explicação alternativa para deposição dos diamictitos maciços seria através de fluxo de detritos
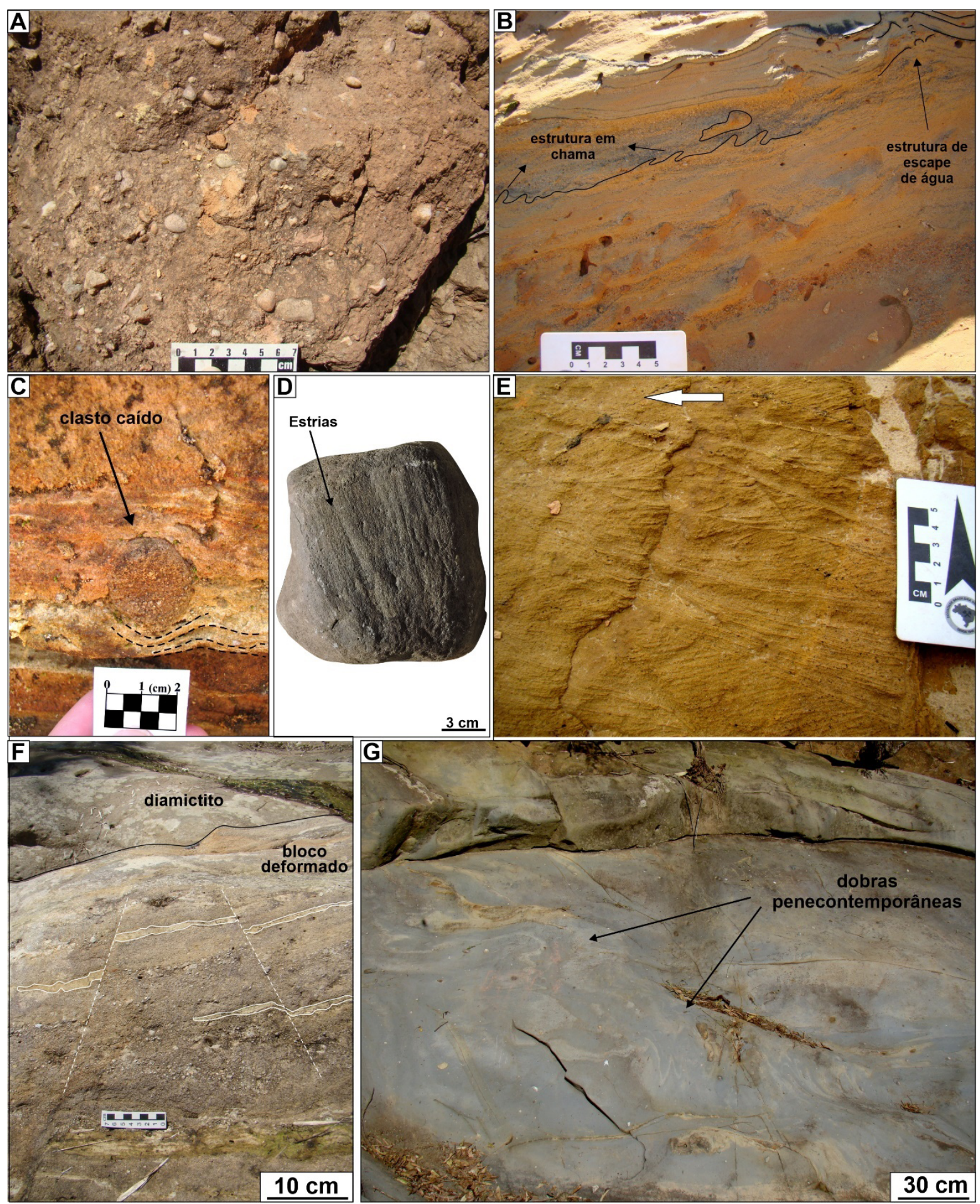

Figura 4 - Principais características da unidade 1. A) Arenito maciço com clastos, Sm2. B) Deformações de sedimentos inconsolidados (soft-sediment deformation) em meso-escala, Ss. C) Clasto caído de granito em arenito com laminação horizontal, Sh. D) Clasto fortemente estriado presente em fácies de diamictito ressedimentado. E) Arenito com climbing-ripples; A seta indica o sentido do paleofluxo. F) Bloco deformado de arenito conglomerático em diamictito da fácies Dres. Note falhas normais deslocando lentes de arenito fino. G) Dobras penecontemporâneas em diamictito da fácies Dres. 
deflagrados por desestabilização dos taludes íngremes intrínsecos aos sistemas de outwash (e.g., Henry et al., 2012).

A deposição dos diamictitos com feições de ressedimentação que ocorrem no topo desta unidade ocorreu por meio de escorregamentos (slumps) em ambiente proglacial distal. Esta interpretação é baseada na presença de abundantes estruturas deformacionais penecontemporêneas, como dobras, falhas, blocos alóctones internamente deformados e injetitos arenosos. A presença de clastos estriados e facetados indica uma fonte de suprimento glacial para estes sedimentos, anteriormente ao seu retrabalhamento e deposição por processos de transporte em massa (e.g., Gama Jr. et al., 1992; Mottin et al., 2018). Blocos alóctones de conglomerados e arenitos são composicionalmente e estruturalmente semelhantes às fácies da própria unidade 1 , indicando, portanto, incorporação do substrato no decorrer do fluxo gravitacional.

Os sistemas de outwash da unidade 1 foram construídos na direção oposta da retração da margem glacial. Estratificações cruzadas e ondulações de corrente em fácies desta unidade indicam que os fluxos de água de degelo fluíram de NE para SW (Fig. 3), o que sugere uma fonte glacial localizada a nordeste da área de estudo (Mottin et al., 2018).

\section{Unidade 2: Depósitos deltaicos (Fm, R, Hf, St1, Sp, Sg,} Sm1, Sh, Sr)

A unidade 2 é caracterizada por um padrão de granocrescência ascendente bem evidente, em que lamitos e ritmitos areno-lamosos são gradativamente sucedidos por fácies arenosas, culminando com pacote arenoso que distingue o topo da unidade (Figs. 2 e 3). Sua espessura é bastante variável, entre 25 e $60 \mathrm{~m}$. No nordeste da área de estudo ocorrem as maiores espessuras, onde o ritmito basal perfaz grande parte do empilhamento estratigráfico. Argilito maciço (espessura $\mathrm{cm}$ ) ou ritmitos assentam abruptamente sobre o diamictito do topo da unidade 1. Na parte superior da unidade 2, os arenitos também ocorrem em contato abrupto sob diamictitos da unidade 3.

Os ritmitos exibem ondulações de corrente unidirecionais ou com reversão de fluxo e drapes de argila (Fig. 5A; C). Laminação horizontal ocorre subordinadamente. A fácies de ritmito passa gradualmente a heterolitos arenosos com acamamento flaser (Fig. 5B). Clastos caídos diminuem em abundância para o topo desse intervalo (Fig. 3), sendo constituídos por grânulos a seixos de rochas cristalinas, sobretudo granitos e quartzitos. Ondulações medidas em ritmitos da unidade 2 mostram paleofluxo principal para $\mathrm{SW}\left(\mathrm{x}=218^{\circ}\right)$.

O pacote superior arenoso é composto sobretudo por arenitos finos a conglomeráticos, mal selecionados e imaturos, intercalados a raras camadas de argilito maciço (poucos mm). As estruturas sedimentares mais comuns nas fácies arenosas são estratificações cruzadas acanaladas e planares, de pequeno a médio porte (Fig. 5D-F), que indicam paleocorrente principal para $\mathrm{SW}\left(\mathrm{x}=240^{\circ}\right)$. Outras estruturas ocorrem subordinadamente, incluindo estrutura maciça, gradada, laminação horizontal e ondulações. Estas últimas exibem paleocorrente principal para $\mathrm{NE}\left(\mathrm{x}=50^{\circ}\right)$, no sentido oposto daquele indicado pelas formas de leito de maior porte.
A unidade 2 registra um padrão de granocrescência ascendente bem definido, interpretado aqui como resultado de uma progradação deltaica, em que dois elementos deposicionais do sistema deltaico podem ser distinguidos. A parte inferior é resultado da deposição por fluxos hidrodinâmicos associados à suspensão de sedimentos lamosos em um contexto de frente deltaica influenciada por maré. A influência de maré é atestada pela presença de ondulações com paleocorrentes bidirecionais (e.g., Willis et al., 1999), drapes argilosos nos foresets das laminações, indicando flutuação na velocidade das correntes e deposição de lama durante os períodos de água parada (e.g., Boyd et al., 2006), e presença de acamamento heterolítico (e.g., Tänavsuu-Milkeviciene e Plink-Björklund, 2009). A diminuição vertical na quantidade de clastos caídos sugere um decréscimo progressivo da influência glacial dentro da unidade 2 .

O intervalo superior da unidade 2, que é uma continuação do intervalo hetetolítico basal na forma de uma granocrescência ascendente, é resultante da deposição em um ambiente de planície deltaica, ocasionalmente influenciada por maré. O estilo dos canais fluviais é interpretado como do tipo entrelaçado, devido à predominância de fácies de granulação grossa, pela presença de diversos ciclos de gradação normal e baixo conteúdo de lama, o que sugere planícies de inundação pouco desenvolvidas (e.g., Coleman e Prior, 1982; Liangqing e Galloway, 1991). A atividade de maré neste ambiente é evidenciada por paleocorrentes bidirecionais (Fig. 3), ritmicidade em estratificações cruzadas planares em que são observados ciclos de aumento e diminuição da espessura dos estratos cruzados (e.g., Choi, 2011; Longhitano et al., 2012; Fig. E) e drapes argilosos em foresets de estratificações cruzadas (Fig. E).

Depósitos deltaicos da unidade 2 (ritmitos e arenitos) apresentam paleotransporte fluvial predominante para SW, indicando uma área-fonte localizada a nordeste da área de estudo, semelhante à unidade 1 (Mottin et al., 2018). Contudo, fluxo subordinado para NE, principalmente extraído de ondulações de corrente em arenitos de planície deltaica, sugerem retrabalhamento por correntes de maré enchente nessa direção.

\section{Unidade 3: Depósitos glácio-marinhos ressedimentados (Dm, Dres)}

A unidade superior da Formação Taciba, com espessuras de até $40 \mathrm{~m}$, encerra o empilhamento estratigráfico do Grupo Itararé na área de estudo (Fig. 3). É composta por diamictitos maciços e diamictitos com feições de ressedimentação (Fig. 6). Em geral, os diamictitos possuem matriz de granulação argila a areia fina, pobres $(<5 \%$; predominantes) a ricos ( $>5 \%$ ) em clastos (Hambrey \& Glasser, 2012), que variam em dimensão de grânulo a bloco (até $45 \mathrm{~cm}$; Fig. 6A). Os clastos são compostos principalmente de granito, quartzito, quartzo e arenito. São comuns clastos facetados, estriados e em forma de ferro de engomar, além de clastos arredondados exibindo uma ou mais faces polidas contendo estrias (Fig. 6B).

Diamictitos ressedimentados apresentam abundantes blocos alóctones de ritmito e arenito (fino a cascalhoso; Figs. 3E e 6C), os quais podem guardar estruturas 
sedimentares primárias, geralmente estratificações cruzadas acanaladas. Os blocos alóctones apresentam baixos mergulhos e dimensões variáveis, desde poucos centímetros até $20 \mathrm{~m}$.

Fácies mal selecionadas (diamictitos) e ricas em estruturas de deformação plástica (e.g., falhas, dobras, injectitos, blocos deformados) sugerem um contexto de fluxo gravitacional de massa subaquoso para a deposição da unidade 3 .
Estas estruturas são relacionadas a processos de ressedimentação por escorregamentos, que envolvem deformações internas do material conforme a massa se move talude abaixo (Shanmugam, 2006; Posamentier \& Martinsen, 2011). Clastos facetados e estriados foram depositados originalmente através de icebergs, e posteriormente incorporados no fluxo de massa. Os blocos alóctones de ritmito e arenito presentes nos diamictitos ressedimentados
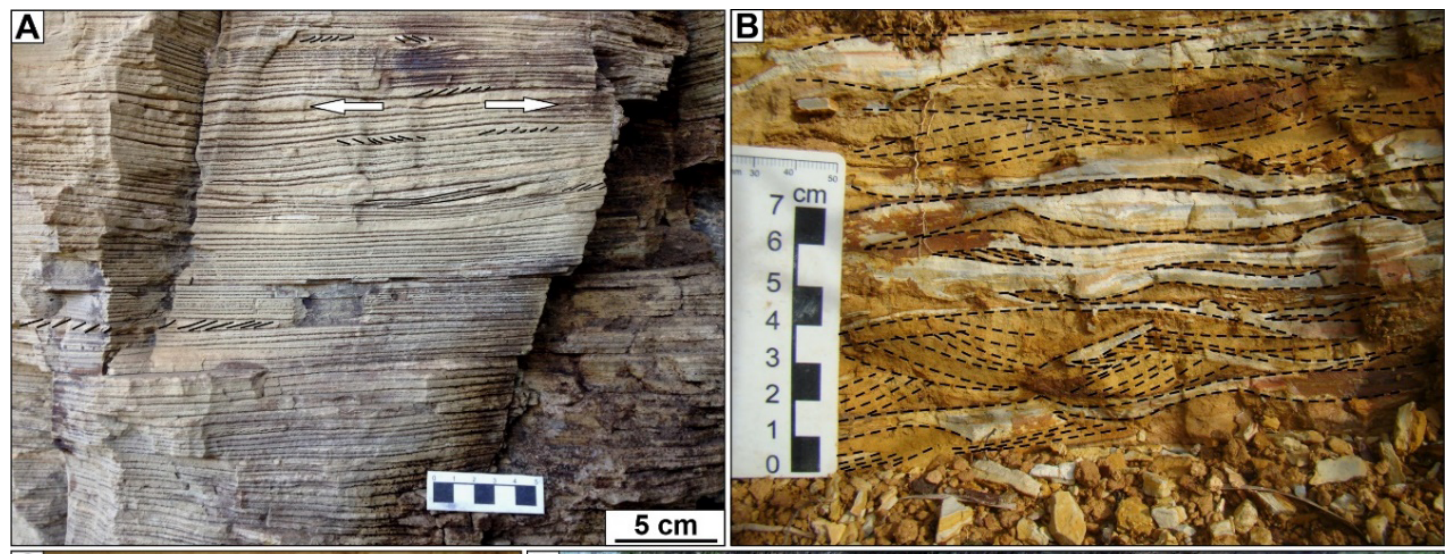

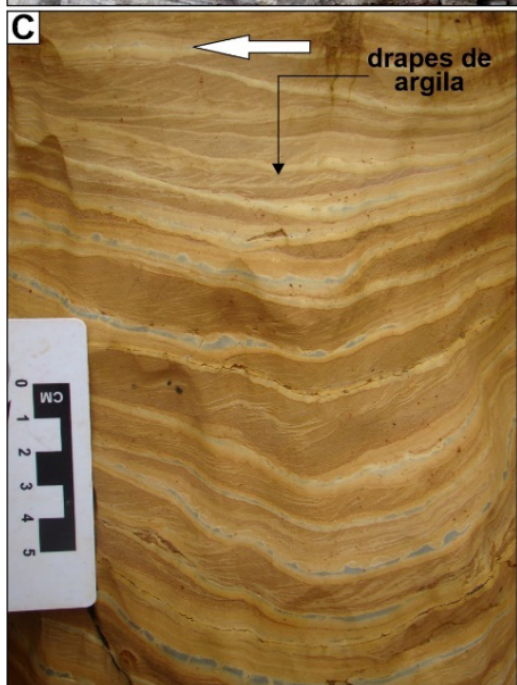

$\bar{E}$

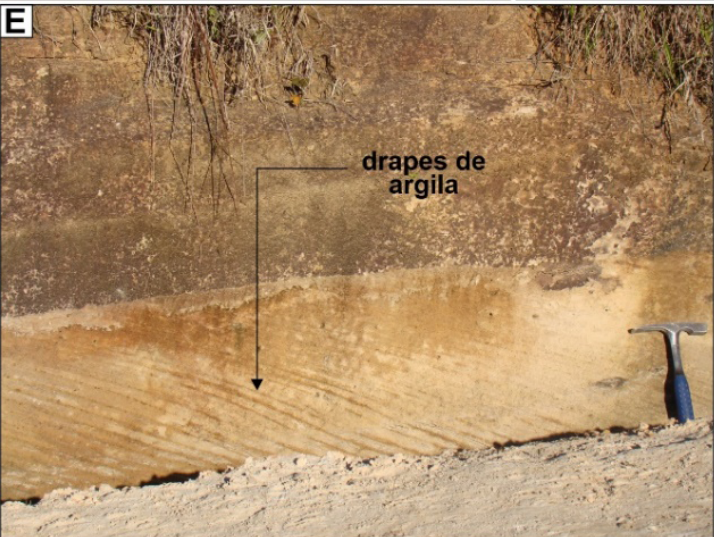

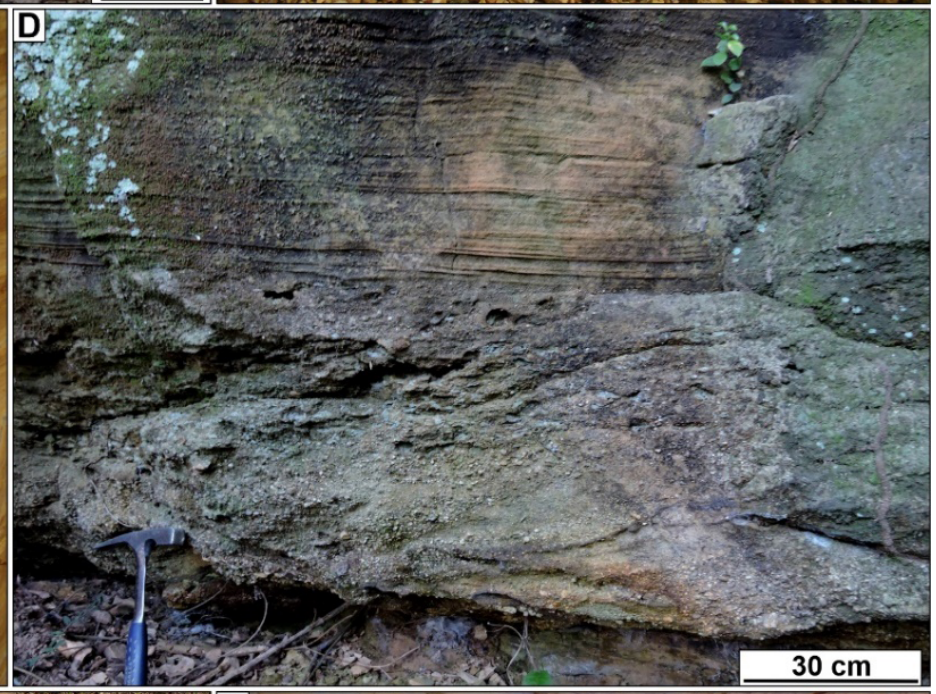

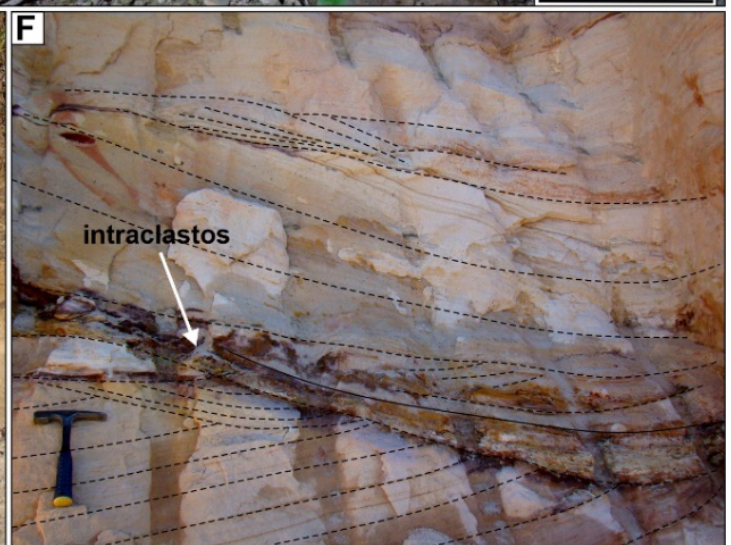

Figura 5 - Principais fácies da unidade 2. (A) Ritmito síltico-arenoso com espaçamento subcentimétrico e ripples bidirecionais. As setas indicam direções de paleotransporte. (B) Heterolito com acamamento flaser, com laminações destacadas por linhas pretas tracejadas. (C) Ritmito síltico-argiloso com ripples e drapes argilosos. (D) Contato entre arenito cascalhoso com estratificação cruzada acanalada, abaixo, e arenito com laminação horizontal, acima. (E) Arenito portando estratificação cruzada planar. Notar foresets com drapes de argila e ritmicidade da estratificação. (F) Arenito com estratificação cruzada acanalada de grande porte. Os planos inclinados avermelhados são enriquecidos em óxidos de ferro e intraclastos de argila. 
são semelhantes às fácies descritas na unidade 2 , subjacente, tendo sido provavelmente incorporados à matriz do diamictito através da erosão do substrato e assimilação dos blocos ao fluxo de massa (Mottin et al., 2018).

\subsection{Natureza do contato com depósitos pós-glaciais da Formação Rio Bonito}

O contato entre os diamictitos da unidade 3, posicionados no topo da Formação Taciba, e conglomerados, arenitos e lamitos associados a carvão, da base da Formação Rio Bonito, registra a passagem definitiva de condições glaciais para condições pós-glaciais no nordeste da Bacia do Paraná. A parte superior da unidade 3, poucos metros do referido contato, é representada por diamictitos maciços de cores roxa a cinza claro, que ocorrem apenas nesse nível estratigráfico. Estas cores estão dispostas em níveis mais ou menos paralelos, com contatos gradacionais entre si (Fig. 6D). Em escala mesoscópica, tais diamictitos apresentam marcas de raízes, além de agregados de blocos de escala centimétrica, formados pela intersecção de planos irregulares revestidos por argila e/ou óxido de ferro. Os diamictitos são sobrepostos abruptamente por arenitos mal selecionados, com estratificações cruzadas e abundantes intraclastos, pertencentes ao Membro Triunfo da Formação Rio Bonito.

Marcas de raízes são consideradas as feições mais distintivas na identificação de um perfil de solo, pois ocorrem necessariamente in situ, indicando que a rocha que as contém foi exposta a condições atmosféricas e colonizada por plantas (Retallack, 1988). Os agregados de blocos são interpretados como estruturas do tipo peds, unidades básicas que compõem um solo. As superfícies que definem os peds são denominadas cutans, e em conjunto com os primeiros, definem a estrutura principal de um solo (Retallack, 1988). Os níveis de colorações distintas em contato gradacional podem constituir horizontes do paleossolo. Dessa forma, tais feições diagnósticas indicam que o limite entre o Grupo Itararé e a Formação Rio Bonito é marcado por um nível de paleossolo bem desenvolvido, o que implica na exposição subaérea dos diamictitos da unidade 3 , formados originalmente em ambiente marinho.

Nesse sentido, a natureza erosiva do contato entre o Grupo Itararé e a Formação Rio Bonito e a ausência de
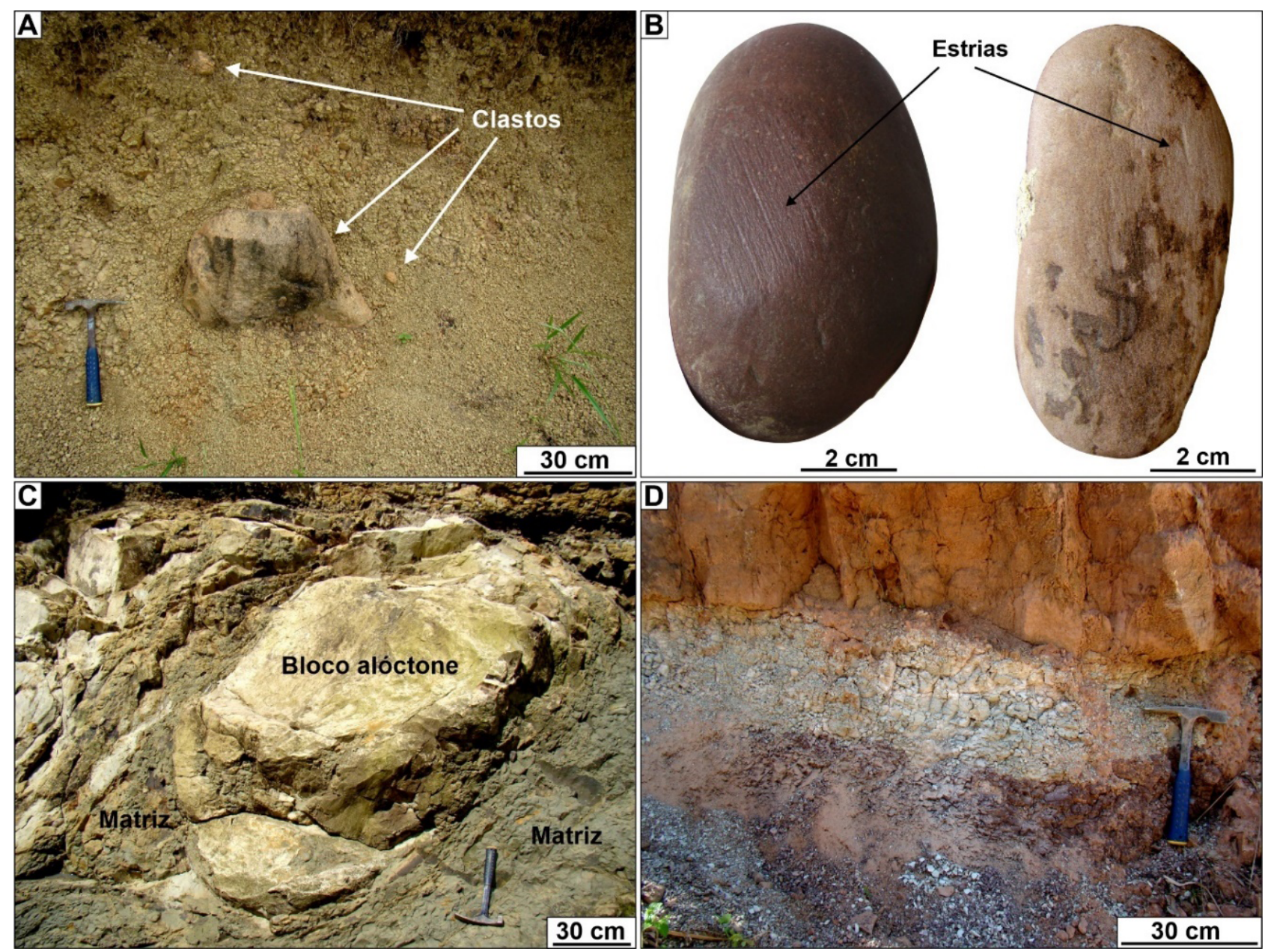

Figura 6 - Depósitos glácio-marinhos ressedimentados. (A) Clastos de granito em diamictito maciço. (B) Clastos arredondados, facetados e estriados recuperados de diamictitos ressedimentados da Unidade 3. (C) Blocos alóctones de arenito fino esbranquiçado em meio a matriz siltíco-arenosa do diamictito. (D) Diamictito maciço próximo ao contato com a Formação Rio Bonito. Note a cor roxa característica na base do diamictito, passando a cinza esbranquiçado. 


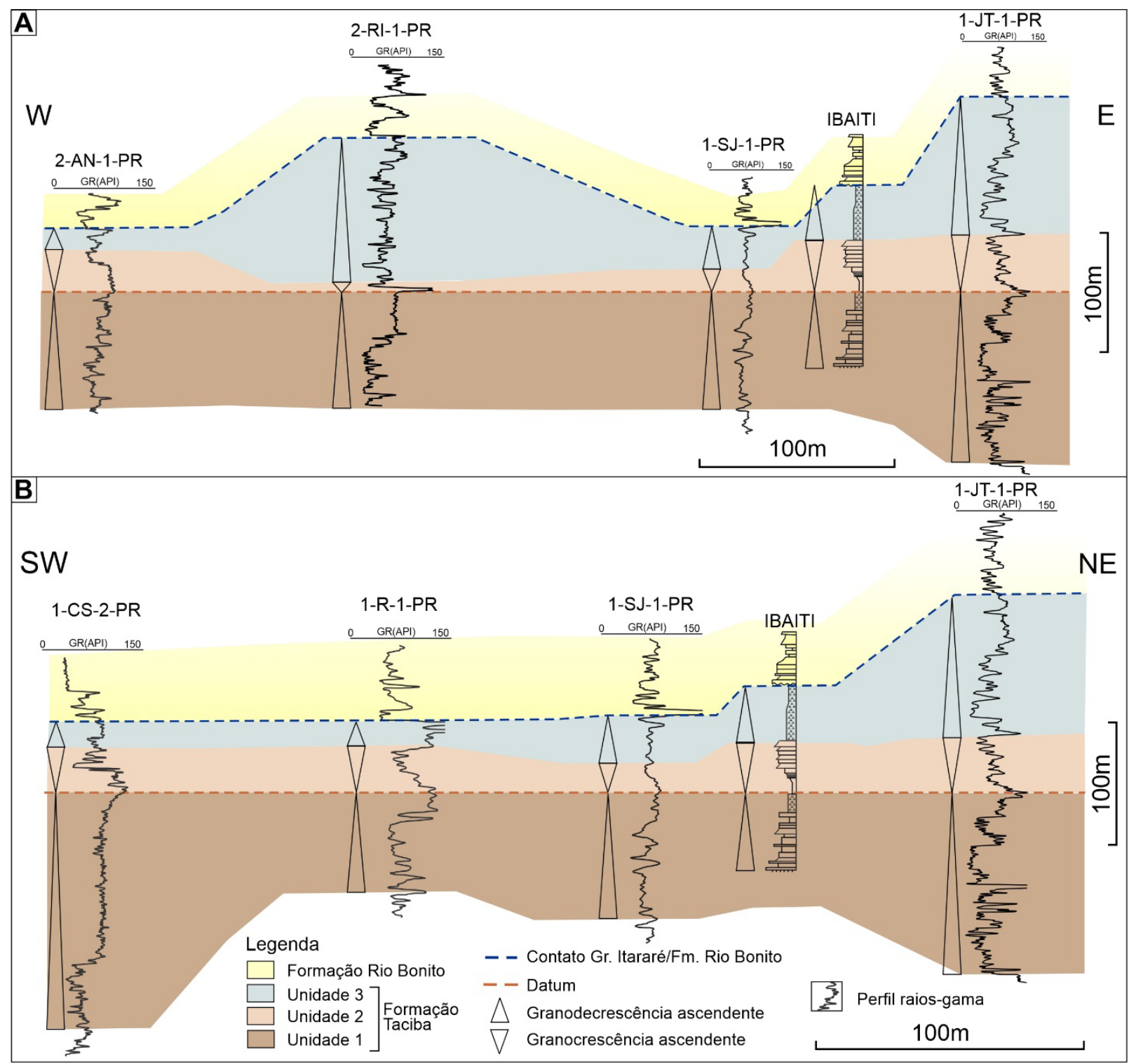

Figura 7 - Correlação estratigráfica da Formação Taciba no Estado do Paraná. A) Correlação E-W entre Joaquim Távora e Altônia, totalizando cerca de $400 \mathrm{~km}$. B) Correlação NE-SW entre Joaquim Távora e Chapéu do Sol, perfazendo aproximadamente $250 \mathrm{~km}$. A localização dos poços e da área de Ibaiti consta na Fig. 1.

fácies e estruturas climaticamente sensíveis nesta última unidade (e.g., diamictitos com afinidade glacial, estratos com clastos caídos) sugerem que condições glaciais não persistiram a partir deste nível estratigráfico.

\section{Correlação Estratigráfica}

Os padrões de empilhamento estratigráfico reconhecidos na Formação Taciba no nordeste do Paraná foram detectados também em poços profundos ao longo de centenas de quilômetros bacia adentro, nas seções E-W e NE-SW (Fig. 7).

As unidades deposicionais estão empilhadas estratigraficamente de modo a formar duas sucessões exibindo granodecrescência ascendente, posicionadas na base e topo do intervalo, intercaladas à uma sucessão intermediária com granocrescência ascendente. Os depósitos proglaciais da unidade 1, caracterizados em afloramento, correlacionam-se lateralmente ao intervalo basal de granodecrescência ascendente, representado em marrom na figura 7. Nesse sentido, o pacote areno-cascalhoso corresponde ao intervalo com baixa radioatividade da base da unidade. Este intervalo com baixas contagens de raios-gama passa progressivamente a um intervalo com padrão serrilhado no topo, que apresenta contagens de raios gama relativamente mais elevadas, e que se correlaciona ao pacote de diamictito do topo da unidade 1 (Fig. 7).

$\mathrm{O}$ contato entre as unidades 1 e 2 é abrupto, marcado pelo pico de alta radioatividade que define o datum utilizado da correlação. Este pico é a base da sucessão de granocrescência ascendente da unidade 2 e que na área de estudo corresponde a uma delgada camada de argilito com clastos caídos. O padrão de granocrescência ascendente bem evidente em afloramentos e perfis de poços representa a progradação deltaica que caracteriza o 


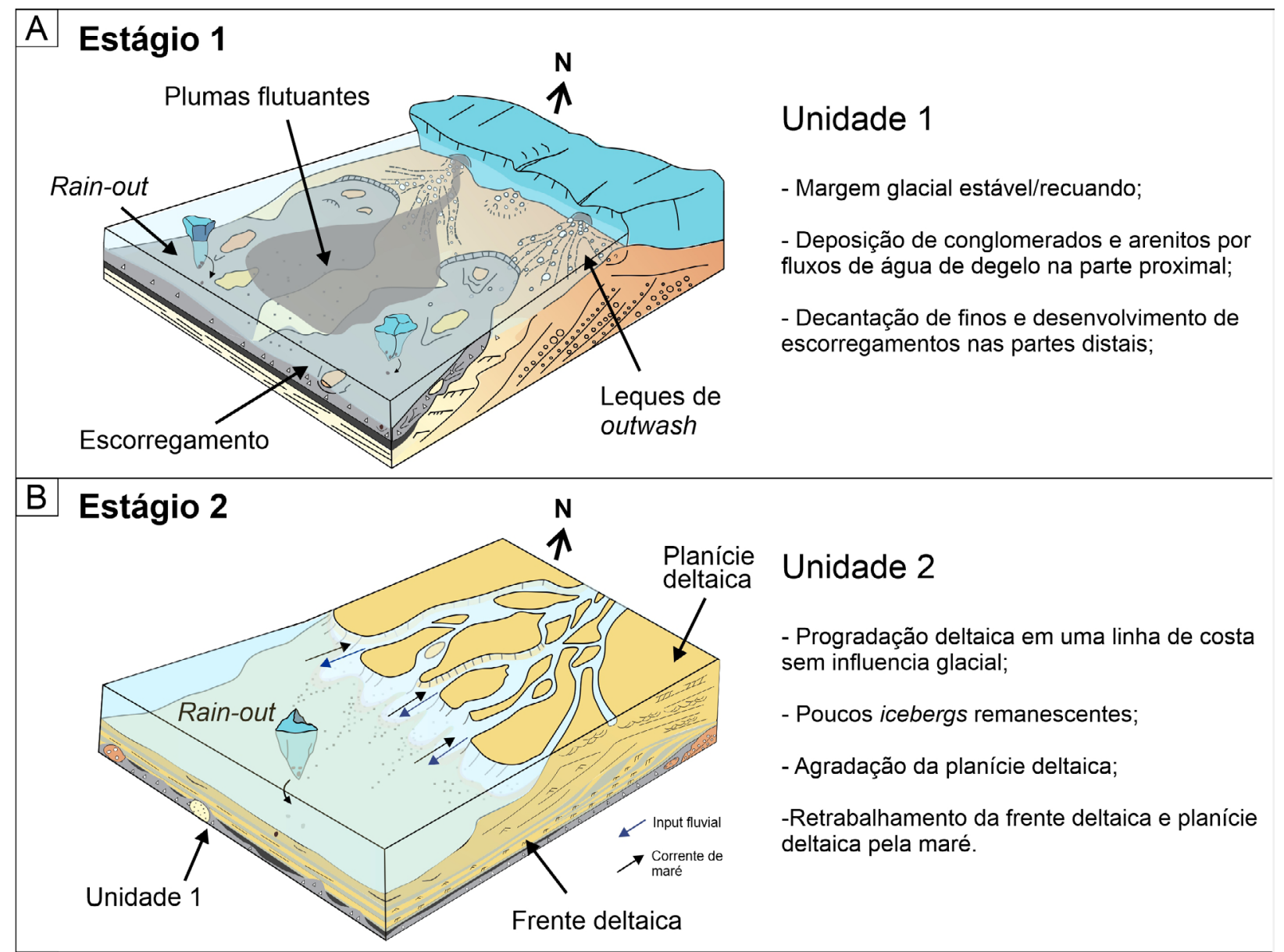

\section{Estágio 3}

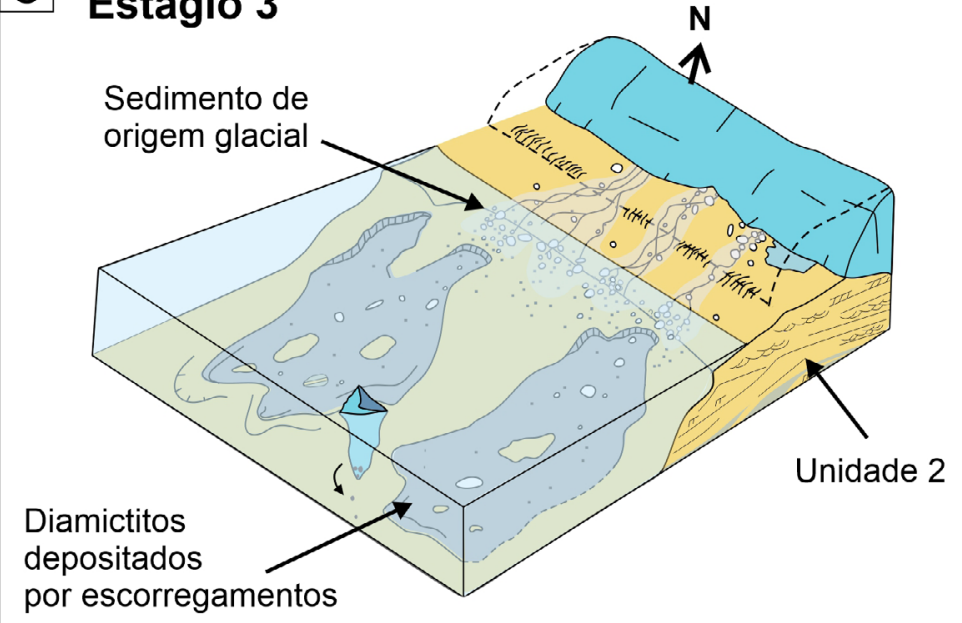

\section{Unidade 3}

- Margem glacial em retração;

- Ressedimentação via escorregamentos envolvendo sedimentos de origem glacial + substrato (ritmitos e arenitos da Unidade 2)

Figura 8 - Reconstrução da história deposicional da Formação Taciba na região nordeste do Paraná. A) Deposição da unidade 1 em frente a uma margem glacial de base úmida em contato com bacia sedimentar marinha. B) Estágio interglacial marcado por importante progradação deltaica que originou a unidade 2. C) Reavanço da margem glacial e posterior retração, com formação da unidade 3 na fase de deglaciação.

empilhamento da unidade 2. O pico basal de argilosidade, embora sutil em afloramentos, apresenta notável extensão lateral, estendendo-se por centenas de quilômetros para oeste e sudoeste (Fig. 7).

A passagem da unidade 2 para a 3 é marcada nos perfis pela inversão do padrão de empilhamento, em que a tendência progradacional da unidade 2 sofre uma inflexão à direita, tendo início um padrão de empilhamento retrogradacional que caracteriza a unidade 3 . A unidade 3, a exemplo da unidade 1, apresenta um padrão serrilhado, que parece ser típico de diamictitos, com altas a moderadas contagens de raios-gama. Picos de baixa radioatividade podem representar corpos de arenitos, sob a forma de intercalações ou mesmo blocos alóctones. 
O contato entre o Grupo Itararé e a Formação Rio Bonito é abrupto, marcado por uma mudança do padrão de empilhamento estratigráfico, em que a granodecrescência ascendente e altas contagens de raios gama, típicas da unidade 3 , passam a contagens notavelmente mais baixas, definindo uma importante inflexão da curva à esquerda devido à entrada dos depósitos arenosos da Formação Rio Bonito (Fig. 7). A base da Formação Rio Bonito é marcada por sucessivos padrões de granocrescência ascendente, que provavelmente referem-se às progradações deltaicas amplamente reconhecidas neste intervalo estratigráfico.

\section{Evolução Estratigráfica}

A deposição da Formação Taciba ocorreu em paleoambientes variando de subaéreo (continental) a marinho relativamente profundo, com níveis variáveis de influência glacial. Contudo, esta influência foi apenas indireta, marcada pela presença de clastos caídos em distintos níveis estratigráficos, diamictitos contendo clastos facetados, estriados e com forma de ferro de engomar e depósitos de outwash. Ambiente marinho é indicado principalmente por evidências sedimentológicas de atividade de maré e presença de algas de afinidade marinha (e.g., Tasmanites sp., Deusilites tenuistriatus and Leiosphaeridia $s p$.) anteriormente relatadas por Mottin et al. (2018).

A identificação do empilhamento estratigráfico das três unidades deposicionais e de suas características distintivas possibilitou a reconstrução da história deposicional do último episódio glacial do Grupo Itararé no nordeste do estado do Paraná. Três estágios evolutivos foram interpretados (Fig. 8), correspondendo à acumulação das unidades 1,2 e 3 . A reconstrução da história deposicional apoiou-se no modelo de Boulton (1990), que contempla fatores como a glácio-isostasia como controle adicional nas mudanças no nível de base durante a evolução de um ciclo glacial. As tendências deposicionais características de cada unidade foram traçadas por até $400 \mathrm{~km}$ bacia adentro, sugerindo um caráter regional para os eventos que resultaram no arcabouço estratigráfico da Formação Taciba.

O estágio 1 representa deposição em contexto proglacial, em frente à uma geleira de base úmida aterrada, estável ou recuando. Durante este estágio, a margem glacial estava relativamente próxima ao sítio deposicional. Em um contexto proximal à geleira, conglomerados e arenitos mal selecionados foram acumulados diretamente pela liberação de fluxos de água de degelo concentrados a hiperconcentrados (e.g., Mulder \& Alexander, 2001; Powell \& Cooper, 2002; Fig. 8A). Em partes mais distais, diamictitos maciços e argilitos foram acumulados pela decantação de lama oriunda de plumas flutuantes carregadas de sedimentos finos e liberação de clastos por icebergs. Já os diamictitos ressedimentados provavelmente resultaram da desestabilização de taludes íngremes dos leques de outwash e deflagração de escorregamentos que envolveram escavação do substrato e incorporação de blocos de conglomerado e arenito (Fig. 8A). Mecanismos de disparo de fluxos gravitacionais de massa em ambientes proglaciais são diversos e podem incluir: alto aporte sedimentar, sismos relacionados ao rebound glácio-isostático e mudanças no nível de base (e.g., Lønne, 1995; Nemec et al., 1999; van Loon et al., 2016; Dietrich et al., 2017).

O estágio 1 corresponde ao primeiro ciclo de deglaciação da Formação Taciba e os lamitos com clastos caídos utilizados como datum na correlação estratigráfica representam a fase final deste ciclo. Com a retração definitiva da margem glacial, um aumento glácio-eustático é esperado (e.g., Boulton 1990; Dietrich et al., 2017), culminando com uma transgressão, em que o datum representaria a máxima inundação. O padrão de granodecrescência ascendente observado na unidade 1 (Fig. 7) é típico de sequências de fácies de deglaciação (e.g., Vesely e Assine, 2006; Dietrich et al., 2017). O fato de o padrão de empilhamento ser correlacionável por centenas de quilômetros, tanto ao longo da direção quanto do mergulho deposicional, corrobora um controle glácio-eustático nessa transgressão.

Após o máximo transgressivo, ocorreu regressão normal com progradação deltaica para SW, uma vez que o suprimento sedimentar ultrapassou a subida eustática que se seguiu à deglaciação. A regressão foi interpretada como normal devido ao empilhamento concordante desde os depósitos de prodelta até os de planície deltaica da unidade 2. A quantidade de clastos caídos nesta unidade diminui progressivamente para o topo, o que sugere uma diminuição progressiva da influência glacial durante sua acumulação. Ademais, o desenvolvimento de uma planície deltaica indica a existência de uma linha de costa livre de gelo e recuo da margem glacial para o continente (Fig. 8B).

Os depósitos de planície deltaica da unidade 2 são sucedidos pelos diamictitos maciços e ressedimentados da unidade 3. Esta relação estratigráfica requer um aumento considerável da coluna d'água para que a planície deltaica tenha sido submersa e para que houvesse espaço de acomodação para deposição de mais de $50 \mathrm{~m}$ de diamictitos (Mottin et al., 2018). As fácies de diamictito contém abundantes clastos facetados, estriados e em forma de ferro de engomar, o que sugere uma fonte glacial para estes sedimentos. Deste modo, um novo episódio de avanço glacial (estágio 3) é aventado (Fig. 8C). O avanço glacial possivelmente está geneticamente relacionado ao aumento da coluna d'água requerido para acumulação da unidade 3, pois ajustes glácio-isostáticos podem produzir rápida subsidência crustal, da ordem de $100 \mathrm{~m}$, por até centenas de quilômetros além da margem glacial (e.g., Boulton, 1990; Brookfield e Martini, 1999; Bennett e Glasser, 2009, Rémillard et al., 2017).

Evidências diretas da ação glacial, como depósitos subglaciais, erosão e deformações glaciogênicas não foram identificadas. Dessa forma, supõe-se que a margem glacial não tenha chegado até esta região. Por outro lado, Rocha-Campos et al. (2000) descreveram deformações glaciotectônicas no mesmo nível estratigráfico, na região de Cerquilho-SP, a norte de Ibaiti, que poderiam representar o registro do avanço glacial interpretado para o estágio 3. Ademais, o sentido de movimentação glacial deduzido pelos autores está em consonância com o sentido de paleotransporte geral para 
SW depreendido de depósitos de outwash e deltaicos. A região de Ibaiti provavelmente representa uma área distal em relação à margem glacial, tendo experimentado baixas taxas de deposição glácio-marinha cujos depósitos foram posteriormente ressedimentados originando os diamictitos da unidade 3 .

Os mecanismos admitidos para a deflagração dos fluxos gravitacionais de massa que originaram a unidade 3 são similares aos admitidos para a unidade 1 . Blocos alóctones de ritmitos e arenitos oriundos da unidade $2 \mathrm{em}$ meio aos diamictitos da unidade 3 sugerem que durante a evolução do escorregamento houve importante erosão do substrato e incorporação daquelas litologias no fluxo (e.g., Moscardelli et al., 2006; Buso et al., 2015; Sobiesiak et al., 2018).

A transgressão marinha associada à deglaciação do estágio 3 não está preservada na área de estudo, uma vez que o topo da Formação Taciba é truncado por discordância. Uma queda acentuada do nível de base levou à exposição subaérea dos diamictitos da unidade 3 , formação de paleossolos a partir destas rochas e colonização por plantas. Esta discordância marca o contato entre o Grupo Itararé e a Formação Rio Bonito, e, portanto, a passagem de um estágio glacial para uma fase pós-glacial. A formação de paleossolo neste nível estratigráfico certamente ocorreu em paralelo ao desenvolvimento de vales incisos reconhecidos por autores como Soares \& Cava (1982) e Zacharias (2004). A presença de paleovales foi principalmente sugerida por: i) descontinuidade lateral de associações de fácies areno-cascalhosas da base do Membro Triunfo, que ocorrem exclusivamente no talvegue de vales escavados no topo do Grupo Itararé (Soares \& Cava, 1982; Zacharias, 2004); ii) diferenças de espessura da Formação Rio Bonito ao longo da região de Ibaiti (Zacharias, 2004); iii) isópacas de carvão mostrando paleovales alinhados N-S e camadas de carvão depositadas lateralmente, no que seriam antigas planícies de inundação (Silva, 1984; Zacharias, 2004).

\section{Conclusões}

O último estágio glacial no estado do Paraná é registrado como um intervalo sedimentar com espessura de aproximadamente $150 \mathrm{~m}$, litoestratigraficamente equivalente à Formação Taciba, unidade superior do Grupo Itararé.

O empilhamento estratigráfico definido na região nordeste do estado do Paraná revela a presença de uma margem glacial dinâmica, marcada por ciclos de avanço e recuo.

Pelo menos dois pulsos de glaciação estão registrados, separados por um estágio de mínima influência glacial e formação de deltas.

Forças glácio-isostáticas tiveram papel importante na criação de espaço de acomodação e como gatilhos para fluxos gravitacionais de massa que deram origem a diamictitos ressedimentados.

A passagem para condições pós-glaciais é estratigraficamente abrupta, marcada por exposição subaérea, desenvolvimento de paleossolo sobre diamictitos e formação de vales incisos.

\section{Agradecimentos}

Os autores são gratos ao Conselho Nacional de Desenvolvimento Científico e Tecnológico (CNPq), pelo suporte financeiro ao projeto 461650/2014-2 e à Capes pela bolsa de estudos concedida à T.E. Mottin entre 2015 e 2017. F.F. Vesely. agradece ao CNPq pela concessão de bolsa de pesquisa (processo PQ 303119/2020-9).

\section{Referências}

ALLEN J.R.L. 1982. Sedimentary Structures: Their Character and Physical Basis. Elsevier, Amsterdam, 663p.

AQUINO C.D., BUSO V.V., FACCINI U.F., MILANA J.P., PAIM P.S.G. 2016. Facies and depositional architecture according to a jet efflux model of a late Paleozoic tidewater grounding-line system from the Itararé Group (Paraná basin), Southern Brazil. Journal of South America Earth Sciences, 67: 180-200.

BENNETT M.R., GLASSER N.F. 2009. Glacial Geology: Ice Sheets and Landforms. Wiley-Blackwell, New York, 385p.

BOULTON G.S. 1990. Sedimentary and sea level changes during glacial cycles and their control on glaciomarine facies architecture. In: DOWDESWELL J.A., SCOURSE J. D. (eds.). Glacimarine Environments: Processes and Sediments. Geological Society Special Publication, 53:15-52.

BOYD R., DALRYMPLE R.W., ZAITLIN B.A. 2006. Estuary and incised valley facies models. In Posamentier, H.W., Walker, R.G. (eds.). Facies Models Revisited: SEPM, Special Publication, 84:171-234.
BROOKFIELD M.E., MARTINI I.P. 1999. Facies architecture and sequence stratigraphy in glacially influenced basins: basic problems and water level/glacier input-point controls (with an example from the Quaternary of Ontario, Canada). Sedimentary Geology, 123:183-197.

BUSO V.V., MILANA J.P., KNELLER B. 2015. Megadeslizamentos gravitacionales de la Formación Guandacol en Cerro Bola y Sierra de Maz y su relación con la glaciación del Paleozoico tardío, La Rioja, Argentina. Latin American Journal of Sedimentology and Basin Analysis, 22(2):109-133.

CASTRO J.C., WEINSCHÜTZ L.C., CASTRO M.R. 2004. Estratigrafia de sequências das Formações Taciba e Rio Bonito (Membro Triunfo) na região de Mafra/SC, leste da Bacia do Paraná. Boletim de Geociências da Petrobrás. 13(1):27-42.

CAGLIARI J., PHILIPH R.P., BUSO V.V., NETTO R.G., HILLEBRAND P.K., LOPES R.C., BASEI M.A.S., FACCINI U.F. 2016. Age constraints of the glaciation in the Paraná Basin: evidence from new U-Pb dates. Journal of the Geological Society, 173(6):871-874. 
CHOI, K. 2011. Tidal rhythmites in a mixed-energy, macrotidal estuarine channel, Gomso Bay, west coast of Korea. Marine Geology, 280:105-115.

CLEAL C.J., THOMAS B.A. 2005. Paleozoic tropical rainforests and their effect on global climates: Is the past the key to the present? Geobiology, 3:13-31.

COLEMAN J.M., PRIOR D.B. 1982. Deltaic Environments of Deposition. In: Scholle, P. A., Spearing, D. (eds.). Sandstone Depositional Environments. Association of American Petroleum Geologists Memoir, 31:139-178.

DIETRICH P., GHIENNE J. F., SCHUSTER M., LAJEUNESSE P., NUTZ A., DESCHAMPS R., ROQUIN C., DURINGER P. 2017. From outwash to coastal systems in the Portneuf-Forestville deltaic complex (Québec North Shore): anatomy of a forced regressive deglacial sequence. Sedimentology, 64:1044-1078.

FIELDING C.R., FRANK T.D., ISBELL J.L. 2008. The late Paleozoic ice age - A review of current understanding. In: FIELDING C.R., FRANK T.D., ISBELL J.L. (eds.). Resolving the Late Paleozoic Ice Age in Time and Space. Geological Society of America Special Paper, 441:41-57p.

FRANÇA A.B., POTTER P.E. 1988. Estratigrafia, ambiente deposicional e análise de reservatório do Grupo Itararé (Permocarbonífero), Bacia do Paraná (parte 1). Boletim de Geociências da Petrobras, 2:147-191.

GAMA JR. E.G., PERINOTTO J.A.J., RIBEIRO H. J.P.S., PADULA E.K. 1992. Contribuição ao estudo da ressedimentação no Grupo Itararé: tratos de fácies e hidrodinâmica deposicional. Revista Brasileira de Geociências, 22:228-236.

GASTALDO R.A., DIMICHELE W.A., PFEFFERKORN H.W. 1996. Out of the Icehouse into the Greenhouse: a late Paleozoic analogue for modern global vegetational change. GSA Today, 10:1-7.

GRIFFIS N.P., MUNDIL R., MONTAÑEZ I.P., ISBELL J., FEDORCHUK N., VESELY F., IANNUZZI R., YIN Q.-Z. 2018. A new stratigraphic framework built on U-Pb single zircon TIMS ages with implications for the timing of the penuntimate icehouse (Paraná Basin, Brazil). Geological Society of America Bulletin, 130:848-858.

HAMBREY M.J., GLASSER N.F. 2012. Discriminating glacier thermal and dynamic regimes in the sedimentary record. Sedimentary Geology, 251-252:1-33.

HENRY C.L., ISBELL J.L., FIELDING C.R., DOMACK E.W., FRANK T.D., FRAISER M.L. 2012. Proglacial deposition and deformation in the Upper Carboniferous to Lower Permian Wynyard Formation, Tasmania: A process analysis. Palaeogeography, Palaeoclimatology, Palaeoecology, 315/316:142-157.
HOLZ M., SOUZA P.A., IANNUZZI R. 2008. Sequence stratigraphy and biostratigraphy of the Late Carboniferous to Early Permian glacial succession (Itararé subgroup) at the eastern-southeastern margin of the Paraná Basin, Brazil. In: FIELDING C.R., FRANK T.D., ISBELL J.L. (eds.). Resolving the Late Paleozoic Ice Age in Time and Space. Geological Society of America Special Paper, 441:115-129.

HOLZ M., FRANÇA A.B., SOUZA P.A., IANNUZZI R., ROHN R. 2010. A stratigraphic chart of the late Carboniferous/Permian succession of the eastern border of the Paraná Basin, Brazil, South America. Journal of South American Earth Sciences, 29:381-399.

ISBELL J.L., MILLER M.F., WOLFE K.L., LENAKER P.A. 2003. Timing of Late Paleozoic glaciation in Gondwana: Was glaciation responsible for the development of Northern Hemisphere cyclotherms? Geological Society of America Special Papers, 370:5-24.

ISBELL J.L., HENRY L.C., GULBRANSON E.L., LIMARINO C.O., FRAISER M.L., KOCH Z.J., CICCIOLI P.L., DINEEN A.A. 2012. Glacial paradoxes during the Late Paleozoic Ice Age: Evaluating the equilibrium line altitude as a control on glaciation. Gondwana Research, 22:1-19.

KOCH Z.J., ISBELL, J.L. 2013. Processes and products of grounding-line fans from the Permian Pagoda Formation, Antarctica: Insight into glacigenic conditions in polar Gondwana. Gondwana Research, 24(1):161-172.

LAJEUNESSE P., ALLARD M. 2002. Sedimentology of an ice-contact glaciomarine fan complex, Nastapoka Hills, eastern Hudson Bay, northern Québec. Sedimentary Geology, 152:201-220.

LIANGQING X., GALLOWAY W.E. 1991. Fan-delta, braided-delta and the Classification of Delta Systems. Acta Geologica Sinica, 4(4):387-400.

LONGHITANO S.G., MELLERE D., STEEL R.J., AINSWORTH R.B. 2012. Tidal depositional systems in the rock record: A review and new insights. Sedimentary Geology, 279:2-22.

LØNNE I. 1995. Sedimentary facies and depositional architecture of ice-contact glaciomarine systems. Sedimentary Geology, 98:13-43.

MEDEIROS R.A., THOMAZ FILHO A. 1973. Facies e ambientes da Formação Rio Bonito. In: XXVII Congresso Brasileiro de Geologia, Salvador, v. 3, pp. 3-32.

MIALL A.D. 1978. Lithofacies types and vertical profile models in braided river deposits: a summary. In: MIALL A.D. (ed.) Fluvial Sedimentology. Canadian Society of Petroleum Geologists Memoir, 597-604p.

MONTAÑEZ I.P., POULSEN C.J. 2013. The Late Paleozoic Ice Age: An Evolving Paradigm. Annual Review of Earth and Planetary Sciences, 41:629-656.

MOSCARDELLI L., WOOD L., MANN P. 2006. Mass-transport complexes and associated processes in the offshore area of Trinidad and Venezuela. AAPG Bulletin, 90(7):1059-1088. 
MOTTIN T.E., VESELY F.F., DE LIMA RODRIGUES M.C.N., KIPPER F., SOUZA P.A. 2018. The paths and timing of late Paleozoic ice revisited: New stratigraphic and paleo-ice flow interpretations from a glacial succession in the upper Itararé Group (Paraná Basin, Brazil). Palaeogeography, Palaeoclimatology, Palaeoecology, 490:488-504.

MULDER T., ALEXANDER J. 2001. The physical character of subaqueous sedimentar density flows and their deposits. Sedimentology, 48:269-299.

NEMEC W., LØNNE I., BLIKRA L.H. 1999. The Kregnes moraine in Gaudalen, west-central Norway: anatomy of a Younger Dryas proglacial delta in a palaeofjord basin. Boreas, 28:454-476.

POSAMENTIER H.W., MARTINSEN O.J. 2011. The Character and Genesis of Submarine Mass-Transport Deposits: Insights from Outcrop and 3D Seismic Data. In: SHIPP R.C.; WEIMER P., POSAMENTIER H.W. (eds.). Mass-transport deposits in deepwater settings. Sepm Society for Sedimentary, 7-38p.

POWELL R.D., COOPER J.M. 2002. A glacial sequence stratigraphic model for temperate, glaciated continental shelves. In: DOWDESWELL J.A., COFAIGH C. (eds.). Glacier- Influenced Sedimentation on High-Latitude Continental Margins. Geological Society, London, Special Publications, 203:215-244.

RÉMILLARD A.M., ST-ONGE G., BERNATCHEZ P., HÉTU B., BUYLAERT J.P., MURRAY A.S., LAJEUNESSE P. 2017. Relative sea-level changes and glacio-isostatic adjustment on the Magdalen Islands archipelago (Atlantic Canada) from MIS 5 to the late Holocene. Quaternary Science Reviews, 171:216-233.

RETALLACK G.J. 1988. Field recognition of paeosols. Geological Society of America Special Paper, 441:1-28.

ROCHA-CAMPOS A.C., CANUTO J.R., SANTOS P.R. 2000. Late Paleozoic glaciotectonic structures in northern Paraná Basin, Brazil. Sedimentary Geology, 130:131-143.

ROCHA-CAMPOS A.C., SANTOS P.R., CANUTO J.R. 2008. Late Paleozoic glacial deposits of Brazil: Paraná Basin. Geological Society of America Special Papers, 441:97-114.

ROSA E.L.M., VESELY F.F., ISBELL J.L., KIPPER F., FEDORCHUK N.D., SOUZA P.A. 2019. Constraining the timing, kinematics and cyclicity of Mississippian-Early Pennsylvanian glaciations in the Paraná Basin, Brazil. Sedimentary Geology, 384:29-49.

RUSSEL H.A.J., ARNOTT, W.C. 2003. Hydraulic-jump and hyperconcentrated-flow deposits of a glacigenic subaqueous fan: Oak Ridges Moraine, Southern Ontario, Canadá. Journal of Sedimentary Research, 73(6):887-905.

SANTOS P.R., ROCHA-CAMPOS A.C., CANUTO, J.R. 1996. Patterns of late Palaeozoic deglaciation in the Paraná Basin, Brazil. Palaeogeography, Palaeoclimatology, Palaeoecology, 125:165-184.
SCHEMIKO D.C.B., VESELY F.F., RODRIGUES M.C.N.L. 2019. Deepwater to fluvio-deltaic stratigraphic evolution of a deglaciated depocenter: The early Permian Rio do Sul and Rio Bonito formations, southern Brazil. Journal of South American Earth Sciences, 95: 102260 .

SCHNEIDER R.L., MUHLMANN H., TOMMASI E., MEDEIROS R.A., DAEMON R.A., NOGUEIRA A.A. 1974. Revisão estratigráfica da Bacia do Paraná. In: XXVII Congresso Brasileiro de Geologia, Porto Alegre, pp. 41-65.

SHANMUGAM G. 2006. Deep-water Processes and Facies Models: Implications for Sandstone Petroleum Reservoirs. Elsevier, Amsterdam, 496p.

SILVA L.M. 1984. Projeto Sapopema: relatório final de pesquisa. CPRM, São Paulo, 52p.

SOARES P.C., CAVA L.T. 1982. Faciologia e potencial carbonífero da Formação Rio Bonito no norte do Estado do Paraná. In: XXXII Congresso Brasileiro de Geologia, Salvador, v.3, pp. 1120-1134.

SOBIESIAK M.S., KNELLER B., ALSOP G.I., MILANA J.P. 2018. Styles of basal interaction beneath mass transport deposits. Marine and Petroleum Geology, 98:629-639.

SOUZA P.A. 2006. Late Carboniferous palynostratigraphy of the Itararé Subgroup, northeastern Paraná Basin, Brazil. Review of Palaeobotany and Palynology, 138:9-29.

TÄNAVSUU-MILKEVICIENE K., PLINK-BJÖRKLUND P. 2009. Recognizing tide-dominated versus tide-influenced deltas: Middle Devonian strata of the Baltic Basin. Journal of Sedimentary Research, 79: 887-905.

VAN LOON A.J., PISARSKA-KAMROZY M., NARTISS M., KRIEVANS M., SOMS J. 2016. Seismites resulting from high-frequency, high-magnitude earthquakes in Latvia caused by Late Glacial glacio-isostatic uplift. Journal of Palaeogeography, 5(4):363-380.

VESELY F.F., ASSINE M.L. 2004. Seqüências e tratos de sistemas deposicionais do Grupo Itararé, norte do Estado do Paraná. Revista Brasileira de Geosciências, 34:219-230.

VESELY F.F., ASSINE M.L. 2006. Deglaciation sequences in the Permo-Carboniferous Itararé Group, Paraná Basin, southern Brazil. Journal of South America Earth Sciences, 22:156-168.

VESELY F.F., Delgado D., SPISILA L.A., BRUMATTI M. Divisão litoestratigráfica do Grupo Itararé no estado do Paraná. Boletim Paranaense de Geociências (in press).

WEINSCHÜTZ L.C., CASTRO J.C. 2006. Sequências deposicionais da Formação Taciba (Grupo Itararé, Neocarbonífero a Eopermiano) na região de Mafra (SC), Bacia do Paraná. Revista Brasileira de Geociências, 36(2): 243-252. 
WILLIS B.J., BHATTACHARYA S.L., GABEL S.L., WHITE C.D. 1999. Architecture of a tide-influenced river delta in the Frontier Formation of central Wyoming, USA. Sedimentology, 46:667-688.

WINSEMANN J., HORNUNG J.J., MEINSEN J., ASPRION U., POLOM U., BRANDES C., BUßMANN M., WEBER C. 2009. Anatomy of a subaqueous ice-contact fan and delta complex, Middle Pleistocene, North-west Germany. Sedimentology, 56:1041-1076.
ZACHARIAS A.A. 2004. Preenchimento de vales incisos por associações de fácies estuarinas, Formação Rio Bonito, nordeste do Paraná. Dissertação de Mestrado. Pós-Graduação em Geociências e Meio Ambiente, Universidade Estadual Paulista, 99p.

ZACHARIAS A.A., ASSINE M.L. 2005. Modelo de preenchimento de vales incisos por associações de fácies estuarinas, Formação Rio Bonito no norte do Estado do Paraná. Revista Brasileira de Geociências, 35(4):573-583. 